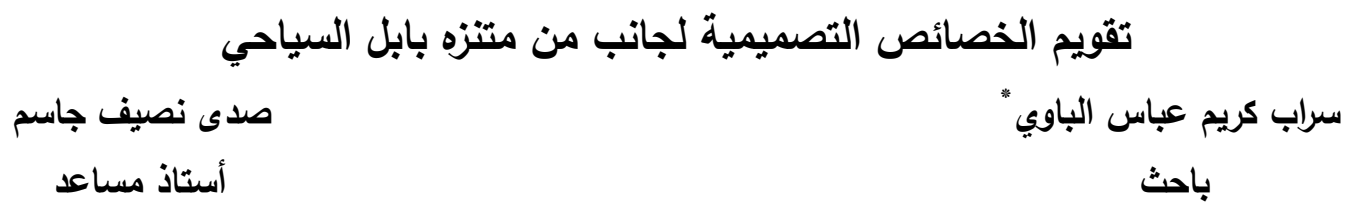

sarabkareem@yahoo.com

$$
\text { قسم البستنة وهندسة الحدائق - كلية الزراعة - جامعة بغداد }
$$

توجه الاهتمام في الاونة الاخيرة نحو أهمية الحدائق والمتنزهات الحضرية كونها من المكونات الاساسية والضرورية نحو تطوير نوعية الحياة الحضرية في المدينة. ان

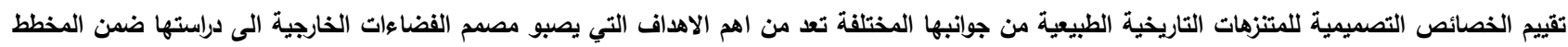

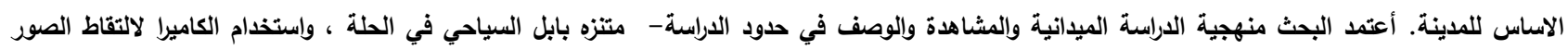

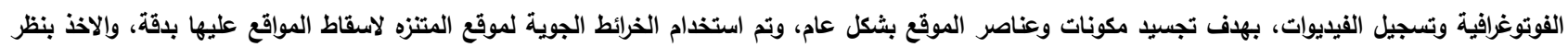

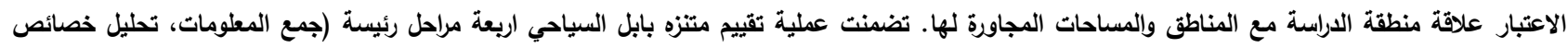

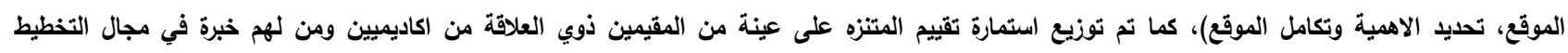

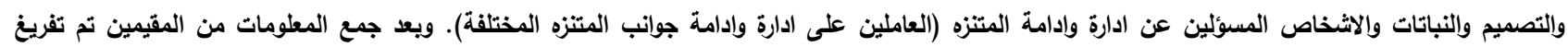

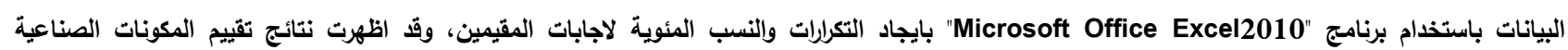

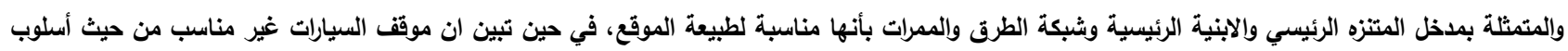

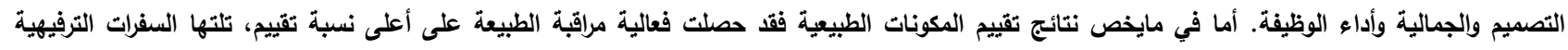

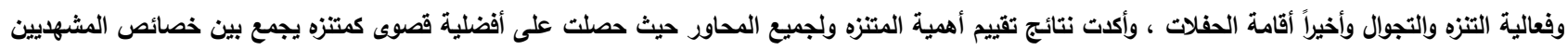

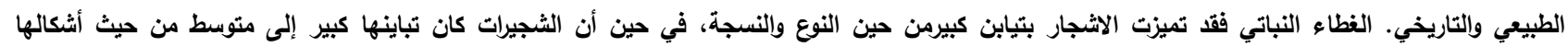

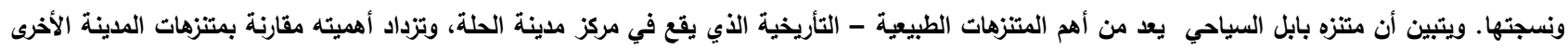

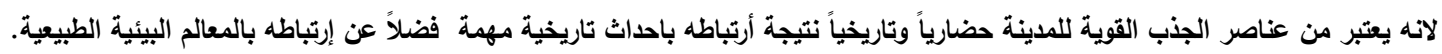

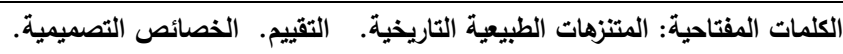
"البحث مستل من رسالة ماجستير للباحث الاول

The Iraqi Journal of Agricultural Sciences - 47(4): 959-972, 2016

Al-Bawi \& Jasim

\title{
EVALUATION OF DESIGN PRINCIPLES FOR BABYLON PARK
}

\author{
S. K. A. Al-Bawi* \\ S. N. Jasim
}

Researcher

Assistant Prof.

sarabkareem@yahoo.com

Dept.Of Horticulture and landscape Gardining Coll. of Agric. , Univ. of Baghdad

\section{ABSTRACT:}

Attention Recently directed to the importance of urban parks and gardens, being one of the basic and essential components to develop quality of urban life. The evaluation of design characteristics of the historical landscape parks from different aspects, one of the most important goals aspires landscape designer to be studied within the master plan of the city. The search adopted field survey methodology and observation, description within limits of current study. Babylon park using the camera and recording videos, in order to embody the components and elements of the overall site, using aerial maps of park site to sketching the sites accurately ,taking into consideration relationship of study area to neighboring areas. Evaluation process of Babylon Tourist Park included four main stages the obtain information,analysis characteristic features, determine the importance and integrity of the site), were also distributed evaluation form on a sample of experience in the planning,design and plants persons responsible for the management and maintenance of the park. After Data were processed using Microsoft office excel 2010. To find duplicates and percentages for evaluators answers. The results for the evaluation for the artificial components (the main gate,the main buildings, the roads and the lanes) were appropriate for the site ,mean while the car park was unsuitable in terms of design aesthetic and functionality regarding the natural components. The effectiveness of the observation of nature got the highest evaluation, followed by recreational travel and the and finally holding concerts and confirmed the importance of evaluating the results of the park and all the interlocutor where you got the utmost preference as a public garden combines with view of natural and historical properties. Vegetation has been characterized by large trees with great differences in the kind and tissue of the tree, while the shrubs was a great contrast to the average in terms of forms and spun.It turns out that Babylon tourist park is one of the most important natural parks historical, which is located in the city of Hilla, center, and increasingly important compared with the gardens of other city because it is one of the elements of the powerful attractions of the city culturally and historically as a result of his involvement in important historical events as well as it relates to environmental and natural monuments.

Key word: - Historical- natural parks - evaluation -design characters.

*Part of M.Sc.thesis of the first author. 
في مركز مدينة الحلة الذي يجاور مدينة بابل الاثرية والتي

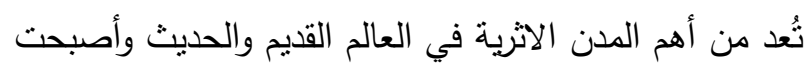
عنوان حضارة وادي الرافدين، تقع على بعد 5 كم شمال مدينة

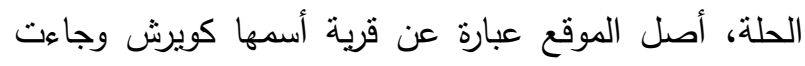
تسميتها نسبة إلى القائد الفارسي كورش الأخميني الذي أحنل

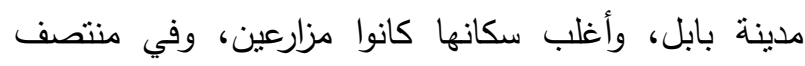
الثنانينيات من القرن الماضي، صدرت الاوامر من الحكومة

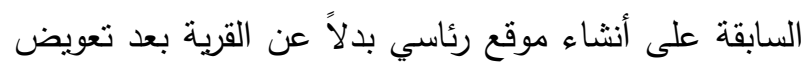
سكانها، وكلفت شركة المعتصم للمقاولات بتشييد نل أطلق عليه " تل صدام" في عام 1989 نم وضع حجر الاساس ولته لنتييد القصر الرئاسي من دائرة الثؤون الهندسية التابعة لديوان الرئاسة وأنتهت آخر مراحل العمل عام 1999، وللفترة من2003-2006 أصبح الموقع تحت سيطرة قوات الأحتلال وسمي أنذاك بمعسكر بابل، أذ تم الاستيلاء على جميع أجزاء

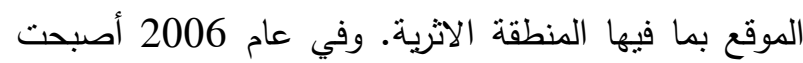
عائدية الموقع لديوان محافظة بابل - قسم ادارة المرافق

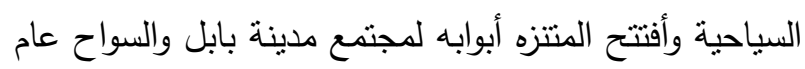

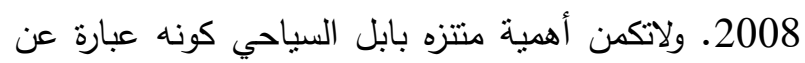
مساحة خضراء تقع في مركز الحلة فقط، بل بتعدى ذلك بأنه واحدة من عناصر الجذب القوية للمدينة حضارياً وتاريخياً.يشير (12) إلى أنه كي يتم تسجيل منل هذه المواقع في السجل الوطني للبلد ويكون مؤهلاً لاجراء دراسة متكاملة

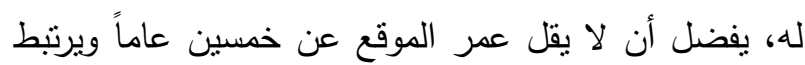

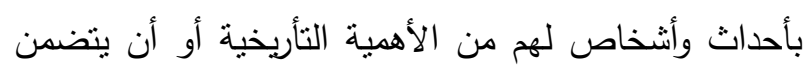

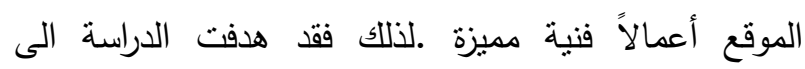

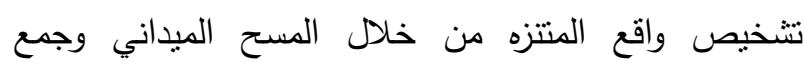
المعلومات المنوفرة عن موقع الدراسة.

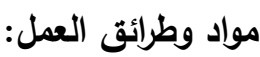

Evaluation الدراسة الميدانية: تقييم متتزه بابل السياحي: of Babylon Tourism Park

يعتمد ثقييم الخصائص التصميمية للمتنزهات التاريخية

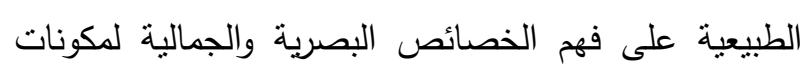

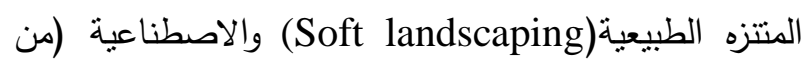

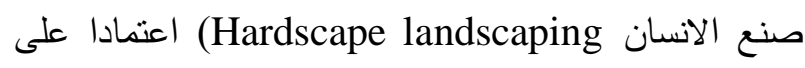
اسلوب تصميمها، المواد المصنوعة منها، وظائفها وملائمتها لطبيعة الموقع وتوزيع هذه المكونات ضمن هيكل المنتزه
المقدمة

"Urban parks" تُعد كل من المتنزهات الحضرية الحمات والمساحات الخضراء Green spaces ذات أهمية في تحسين نوعية الحياة Quality of life لمجتمع المدينة نتيجة لكون هذه المساحات تؤدي العديد من الوظائف المهمة

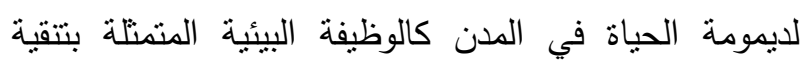
الهواء والماء وتقليل الضوضاء وخفض درجات الحرارة وتوفير

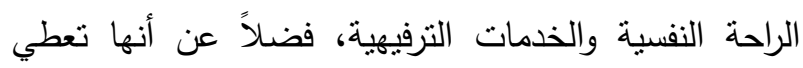
فرصة للإنسان كي يتأمل الطبيعة المحيطة به(15)(19) (7). تبرز أهية المنتزهات الحضرية والمساحات الخضراء كونها جزءاً أساسياً من الأرث الحضري"Urban heritage والبنية البنية التحنية Infrastructure فضلاً عن أنها تساعد على التفاعل الاجتماعي وتتجيع تطوير المجتمع وتوفير صف

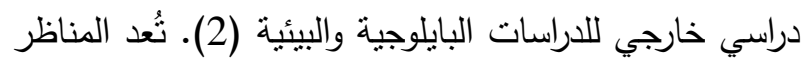
الطبيعية التأريخية Historic Landscape مكاناً مرنبطاً بنشاط أو حدثاً أو شخصاً مهماً تاريخياً لذا يمكن أن تمتلك قيمة تأريخية تتبع من مجموع التاريخ البشري ومن بينها القيم

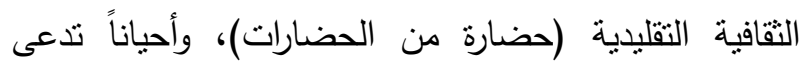
مناظر طبيعية نقافية"Cultural landscapes كمايطلق عليها مناظر طبيعية تراثية Heritage Landscapes"، وتضم موارد طبيعية كالغطاء النباتي وعنصة ونصر الماء والخصائص الطوبوغرافية المتعلقة بسطح الارض ومعالم من موردية صنع الانسان منل المباني، والنصب التذكارية وتتدرج مساحاتها من صغيرة إلى الأف الدونمات، و يمكن أن تكون الانسان المحيط الذي يجاور بناية ذات أهمية تأريخية(11). توجها

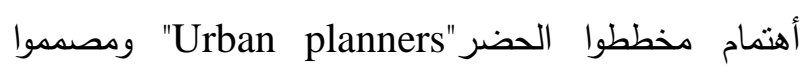
المناظر الطبيعية "Landscape Designers" إلى أهمية “Landscape” المتنزهات التي تجمع بين المشهد الطبيعي الطئي والأرث الحضري وذلك لتطويرها ورفع مستوى الاداء فيها بما

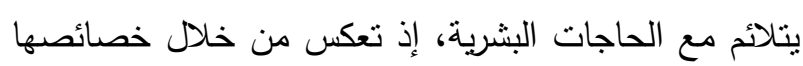

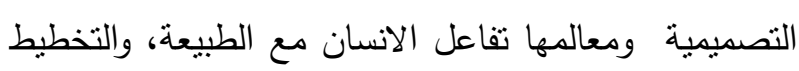
الجيد لهذه المتتزهات يساعد في نشخيص المنظر الطبيعي

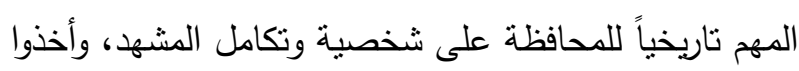
يركزون على كيفية جعلها مواقع مناسبة لإدراك البيئة الطبيعية والإحساس بها (9). يُعد متنزه بابل السياحي أحد

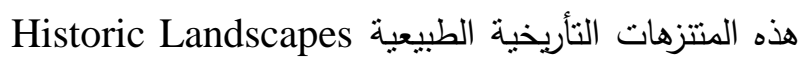


أية مخططات أو وثائق تخص منطقة الدراسة "منتزه بابل

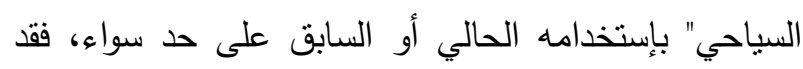
لجأنا إلى أعداد خارطة أساس للموقع" واقع الحال " بالأعتماد

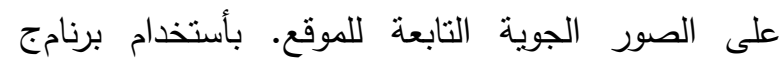
Google earth 1-تم إعتماد الصورة الجوية لموقع المتنزه ومجاوراته من النماثه: برنامج Google earth المحدث عام 2015 بمقياس ،2000/1

2-تم إلتقاط صور Image لموقع المنتزه ومجاوراته، بوساطة الحاسبة (Labtob) لقطة شاشة من الصورة الجوية، وقد بلغ عدد الصور "لقطات الثاشةة" 85 صورة. 3- بعد طباعة الصورة الملتقة نم لصقها ببعضها بحيث يكون التماس صحيحاً ودقيقاً بين صورة وأخرى ومن جميع الجهات وإعادة التدقيق العام لكل من الصور الملصقة والصورة الجوية المعتمدة، وبعد الانتهاء من التجميع لكل الصور ، نتجت صورة واحدة تمثل الموقع بإكمله أبعادها 1.5 × 98 سم.

4- تم سحب الصورة الأخيرة على ورق بإستخدام جهاز

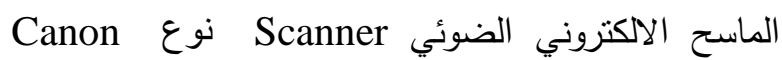
IPF750 5- أعبد تدقيق الصورة المسحوبة مع الصورة الجوية لموقع الدراسة ومجاوراته 6- أدخلت التعديلات على المخطط الورقي وبمايتتاسب مع واقع حال المتنزه (المسح الميداني) مثل تعديل المواقع العسكرية لقوات الاحتلال (كرفانات) وقد حذفت من خارطة الموقع بأستخدام الألوان المائية. 7- نم تحويل المخطط الورقي إلى خارطة موقع بإستخدام برنامج الاوتوكاد وشمل ذلك معالجة وضبط مقياس الرسم

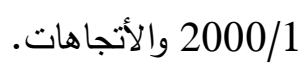
8- أعادة التدقيق العام لاجزاء الموقع كواقع حال مع خارطة

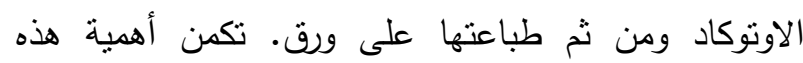

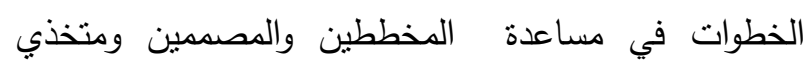

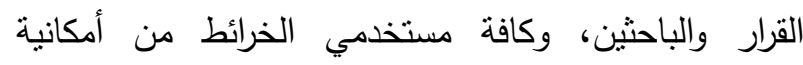

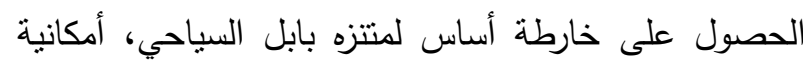
الاضافة والتحديث والتعديل عليها بسهولة.
وعلاقتها مع بعضها البعض من حيث الكتل والفراغات

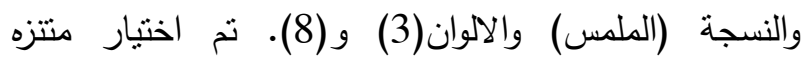
بابل(وسط مدينة الحلة) كي يكون نموذج لنطوير المتنزهات

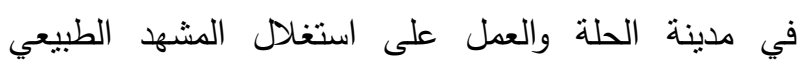
للارض والمشهد الحضاري الموجود في المدينة. لقد اعتمدت

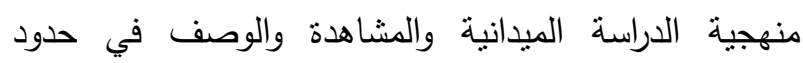

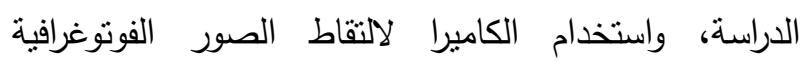
وتسجيل الفيديوات، بهدف تجسيد المكونات والعناصر المكونة للموقع بشكل عام، وتم استخدام الخرائط الجوية لموقع المتنزه لاسقاط المواقع عليها بدقة، والاخذ بنظر الاعتبار علاقة التخام منطقة الدراسة مع المناطق والمساحات المجاورة لها. كما نم

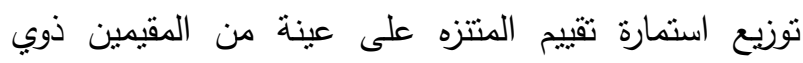
العلاقة من اكاديميين وخبراء ومن لهم خبرة في مجال

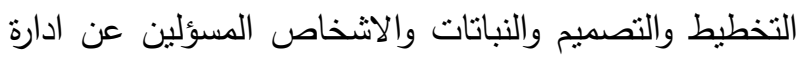
وادامة المتتزه(العاملين على ادارة وادامة جوانب وانب المانب المتنزه

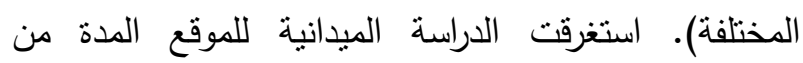
2013/3/6 ولغاية 2015/8/30. وتتشمل الدراسة الميدانية المراحل الثالية:المرحلة الاولى: جمع المعلومات وتتشمل كل مايتعلق بالإستخدام السابق والحالي للمتنزه، كما يأني: 1- الموقع والمساحة: يقع متنزه بابل السياحي في مدينة الحلة ( مركز محافظة بابل)، مجاور لمدينة بابل الاثرية التي تبعد حوالي 5 كم شمال مدينة الحلة، تبلغ المساحة الكلية للمتنزه 120 دونم. 2.سهولة الوصول: يبعد المتتزه عن مركز مدينة الحلة مسافة

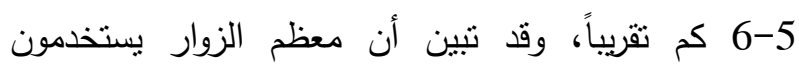
سياراتهم الخاصة، وبعضهم الآخر بسيارات الأجرة، أما الوقت لتصن المستغرق للوصول لايتعدى ثلاثون دقيقة تقريباً (أهالي مدينة الحلة). 3. مواقف السيارات: تبين من خلال المسح الميداني أن المتنزه به موقف واحد فقط للسيارات قرب مدخل الجمجمة الرئيسي للمتتزه، وهوعبارة عن ساحة خارج حدود المتنزه مساحتها 4 دونم أستغلت كموقف للسيارات 4- إعداد خارطة المخطط الأساس المدققة لمنطقة الدراسةتمثل خارطة التصميم الاساس لمتنزه بابل السياحي تمثل

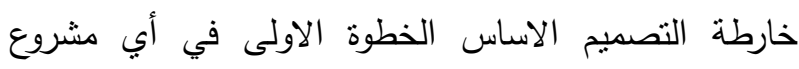

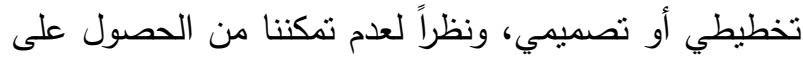




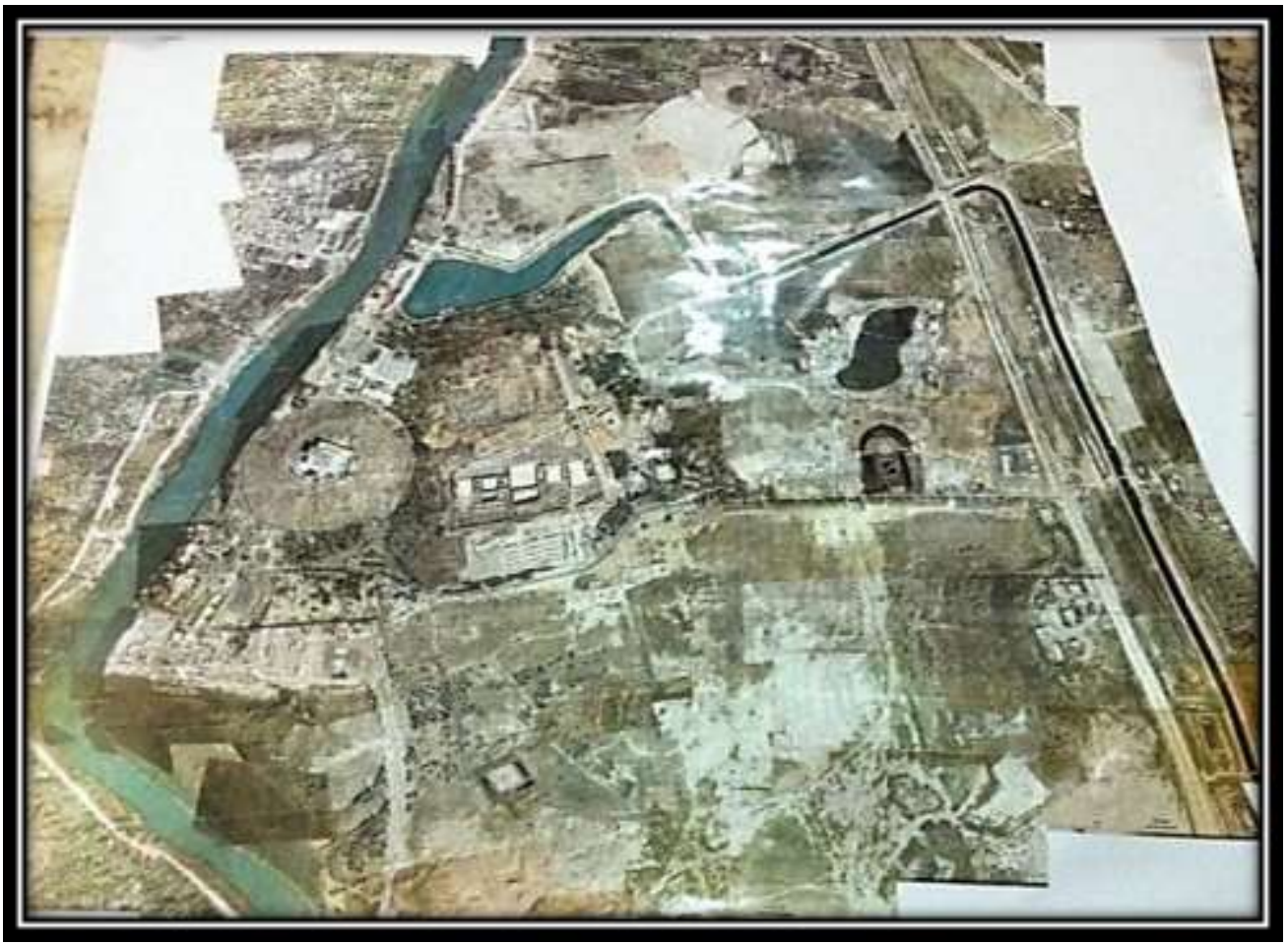

شكل 1. خارطة الموقع ومجاوراته
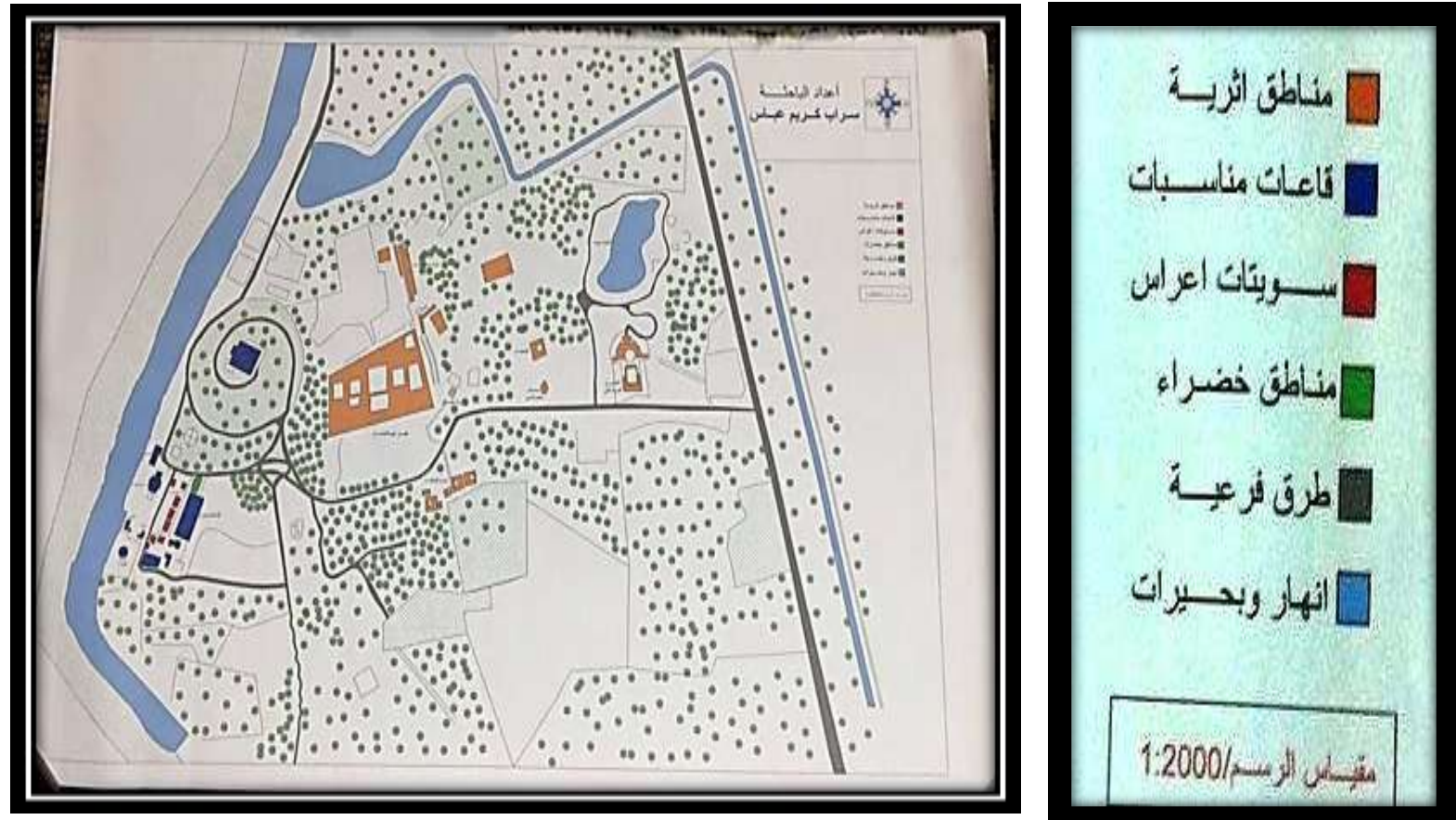

شكل 2. خريطة الموقع ومجاوراته (الاوتوكاد)

وأنسيابيتها وتدرجها من الناحية البصرية، والطرق الرئيسة

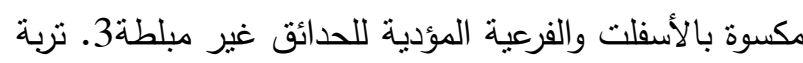
الموقع: أن نسجة تربة الموقع بشكل عام مزيجية غرينية

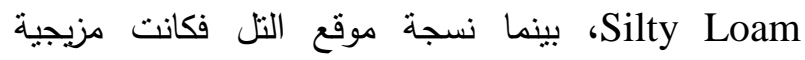

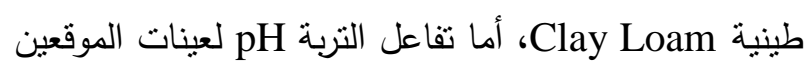
فقد انت متعادلة تقريباً 7.4 ،7.7 على التوالي، جدول نظام الري: يستخدم في المتنزه أكثر من طريقة للري منها
المرحلة الثانية: تحليل خصائص وصفات الموقع وتتضمن أولاً: المكونات الاصطناعية1.المداخل:يتضمن المتنزه ثناثة مداخل، الاول من الجهة الجنوبية - الغربية من قرية الجمجمة (مدخل الجمجمة) المشيد عام 2008، وهو المدخل مله

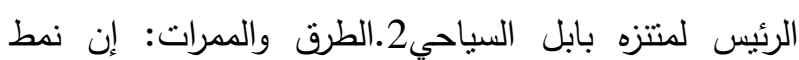
تخطيط الطرق نمط عضوي- طبيعي الذي يستتد على تحقيق الربط بين الطرق الرئيسة والفرعية وتحقيق الاتصال بينها، 
والسمات الطبيعية للموقع: ويقصد بها خصائص وسمات المشهد الطبيعي لمدينة الحلة مثل وجود الطيور المحلية، وحيوانات التربية، ونباتات طبيعية، ومصادر المياه الطبيعية.

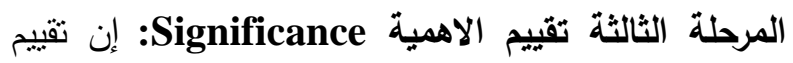
الأهمية Significance هو أرتباط الموقع بأحداث وأثنخاص الهمبه لهم من الأهمية في تطوير تاريخ المجتمع بشكل عام (10). وتم توضيحها في النتائج والمناقثنة.

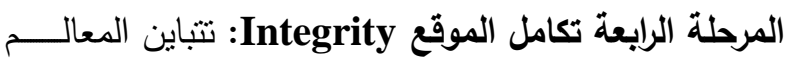

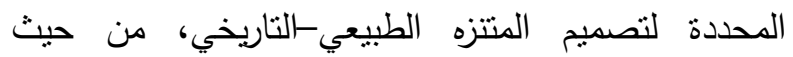

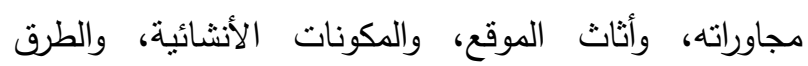

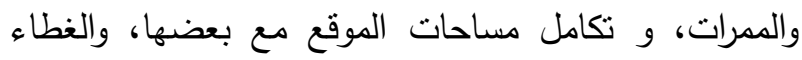
النبات(صفاته، وتوزيعه بمختلف أجزاء الموقع) (14).التكامل

$$
\text { في منل هذه المتنزهات يقسم إلى: }
$$

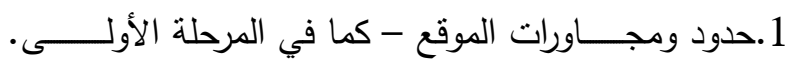

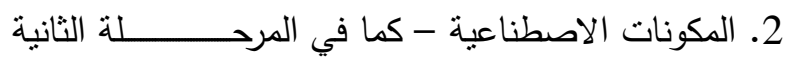

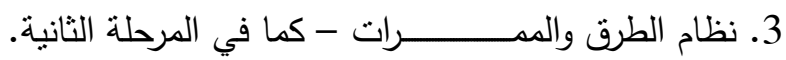

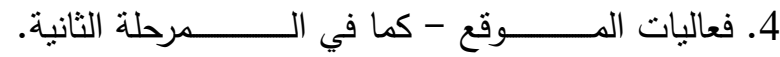
تقييم الغطاء النباتي Vegetation - في المرحلة الرابعة. تستخدم المكونات الطبيعية ( النباتات) من قبل مصمم الحدائق والمتنزهات كعناصر لتحقيق الجمالية والثعور بالمتعة الحسية من خلال التغيرات الموسمية للنباتات ونموها مع مرور الزمن وأنواعها وأشكالها وملمسها والوانها (المجموع

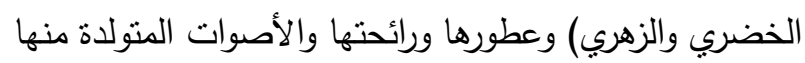
خلال حركة الرياح، جميعها نولد نوعاً من الديناميكية والحيوية للموقع(1) و (4).
الرش، والتنقيط، فضلاً عن الري السيحي وهو النظام السائد،

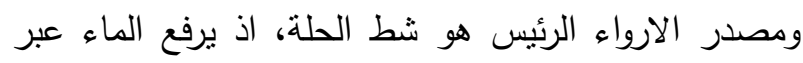
مضخات كهربائية وديزل عن طريق أنابيب حديدية قطر لراء 5 أنج، ويدفع إلى أنابيب أصغر قطراً لغرض توزيع الماء وري لتي حدائق ومساحات المتنزه الخضراء، جدول2. جدول 1. بعض الخواص الكيميائية والفيزيائية لتربة المتنزه التي أجريت تحليلاتها في مختبرات كلية الزراعة / قسم التريةقوالموارد المائية - جامعة بغداد.

\begin{tabular}{|c|c|c|}
\hline تربة الجبل & تربة الحدائق & التحاليز \\
\hline مزيجية طينية & مزيجية غرينية & النسجة \\
\hline 3.1 & 2.5 & EC ds $/ \mathrm{m}$ \\
\hline 7.7 & 7.4 & PH \\
\hline 0.5 & 0.3 & O.M \\
\hline 12.2 & 21.3 & $\mathrm{CaCO}_{3} \%$ \\
\hline 24.4 & 30.4 & $\mathrm{So}_{4} \mathbf{M q} / \mathrm{l}$ \\
\hline 38.0 & 20.0 & $\mathrm{Ca}^{2+} \mathrm{g}$ \\
\hline $\mathbf{5 8 . 0}$ & 44.0 & $\mathbf{M}^{2+} \mathbf{g}$ \\
\hline 1518.0 & 978.0 & Na ppm \\
\hline 03 & 02 & N ppm \\
\hline 25.0 & 26.0 & P ppm \\
\hline 192.2 & 5117. & K ppm \\
\hline 14.10 & 13.10 & $\mathrm{No}_{3} \mathrm{ppm}$ \\
\hline 2.5 & 2.0 & $\mathrm{Hco}_{3} \mathrm{Mq} / \mathrm{l}$ \\
\hline 50.0 & 105.0 & Cl Mq/l \\
\hline 22.1 & 28.9 & طين \\
\hline 52.5 & 51.9 & غرين \\
\hline 25.4 & 20.1 & زميج \\
\hline
\end{tabular}

ثانياً:فعاليات الموقع: من بين الفعاليات التي يقدمها

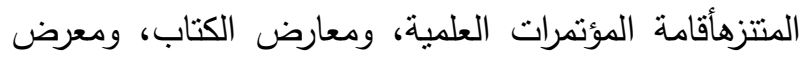

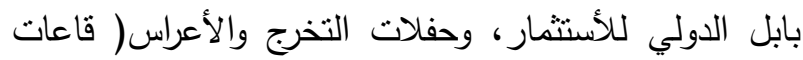

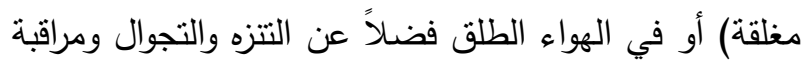

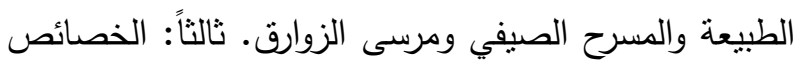

جدول 2. يوضح التحاليل الكيميائية للمياه المستخدمة في ري المتتزه، والتي أجريت تحليلاتها في مختبر مديرية زراعة بابل بتاريخ 2014/7/30.

\begin{tabular}{|c|c|c|c|c|c|c|c|c|c|c|c|c|}
\hline $\begin{array}{c}\mathrm{HCO3} \\
\text { ppm }\end{array}$ & $\begin{array}{l}\text { NO3 } \\
\text { ppm }\end{array}$ & $\begin{array}{c}\mathbf{P} \\
\mathbf{p p m}\end{array}$ & $\begin{array}{c}\mathbf{K} \\
\mathbf{p p m}\end{array}$ & $\begin{array}{c}\text { Na } \\
\text { Ppm }\end{array}$ & $\begin{array}{l}\mathbf{M g}^{2} \\
\mathrm{Me} / \mathrm{l}\end{array}$ & $\begin{array}{l}\mathrm{Ca}^{+2} \\
\mathrm{Me} / \mathrm{l}\end{array}$ & $\begin{array}{l}\mathrm{SO4} \\
\mathrm{me} / \mathrm{l}\end{array}$ & $\begin{array}{c}\mathrm{Cl}^{-} \\
\mathrm{me} / \mathrm{l}\end{array}$ & PH & $\begin{array}{l}\text { E.C. } \\
\text { ds.m }\end{array}$ & التحاليل & ت \\
\hline 1.2 & 2.54 & 0.4 & 10.4 & 148.9 & 2.0 & 2.0 & 16.3 & 2.3 & 7.6 & 0.56 & ماء النهر & 1 \\
\hline 1.3 & 4.20 & 0.4 & 7.7 & 153.7 & 2.4 & 3.0 & 4.0 & 2.7 & 8.0 & 0.48 & ماء خزان التل & 2 \\
\hline 1.0 & 3.60 & 0.4 & 7.8 & 151.0 & 4.0 & 2.0 & 5.0 & 3.0 & 8.0 & 0.48 & ماء التنقيط & 3 \\
\hline
\end{tabular}

خصائص ومميزات وسلبيات الموقع بالاعتماد على ما يتوفر

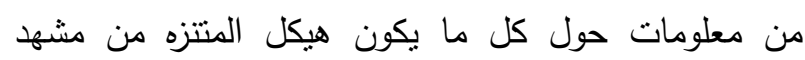

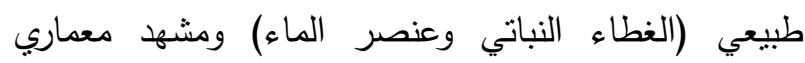
(الابنية- القصر ودار الضيافة ...الخ) ومكونات اصطناعية.
أسلوب التقييم: تبرز اهمية التقييم كونها الاداة التي يمكن من خلالها استطلاع الاراء حول الخصائص التصميمية للجوانب المنتوعة لموقع الدراسة، ولذا فقد قام الباحث باعداد التقييم الخاص بمتنزه بابل السباحي في سبيل فهم وتحديد 
نم تحديد عينة المقيمين باختيار عشرة اشخاص مختلفين في الجدول(3) بعض المعلومات عن المقيمين المشاركين في

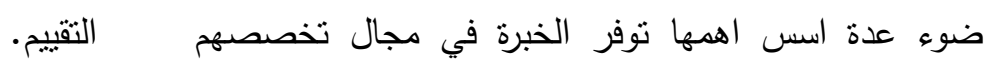

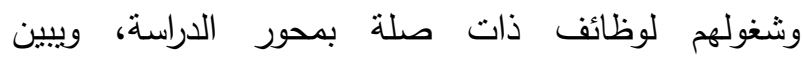

جدول3 .المعلومات الخاصة بالمقيمين

\begin{tabular}{|c|c|c|c|c|c|}
\hline سنوات الخدمة & مجال العمل & التخصص & المرتبة العلمية & الجنس & ت \\
\hline 10 & كلية الزراعة ـ قالخم البستنة_جامعة القاسم & نباتات زينة & استاذ مساعد & ذكر & 1 \\
\hline 10 & كلية الزراعة ـ قسم البستنة_ جامعة تكريت & نباتات زينة & استاذ مساعد & ذكر & 2 \\
\hline 35 & متقاعد- جامعة بغداد & نباتات زينة & 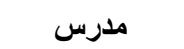 & ذكر & 3 \\
\hline 9 & مدير الثعبة الزراعية في متنزه بابل السياحي & بكلوريوس تربة & - & ذكر & 4 \\
\hline 9 & المعاون الاداري في متّززه بابل السياحي & بكلوريوس محاصيل حقلية & - & ذكر & 5 \\
\hline 9 & المدير الفني لمتنزه بابل السياحي & بكلوريوس بستنة & - & ذكر & 6 \\
\hline 9 & مدير متتزه بابل السياحي & بكلوريوس بستنة & - & ذكر & 7 \\
\hline 25 & كلية الزراعة ـ قسم البستنةـ جامعة بغداد & نباتات زينة & استاذ مساعد & انتى & 8 \\
\hline 20 & كلية الهندسة_ قسم العمارةـ الجامعة التكنولوجية & تصميم فضاءات خارجية & استاذ مساعد & 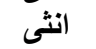 & 9 \\
\hline 30 & كلية الزراعة ـ ق قسم البستنةـ جامعة بغداد & تصميم حدائق & 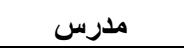 & 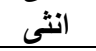 & 10 \\
\hline
\end{tabular}

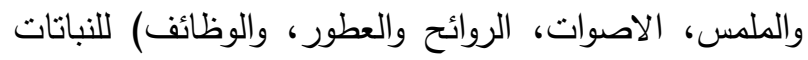

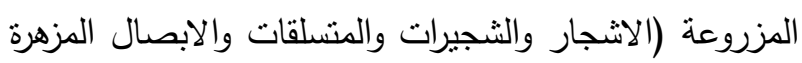

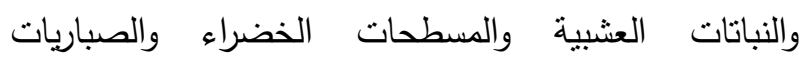
والعصاريات).* بعد جمع المعلومات من المقيمين نم تفريغ

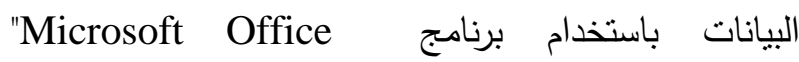
Excel2010"

المقيمين.

النتائج والمناقشة:

اولا: تقييم المكونات الاصطناعية في متنزه بابل السياحي: موقف السيارات: يتبين من جدول4. ان تقييم موقف السيارات

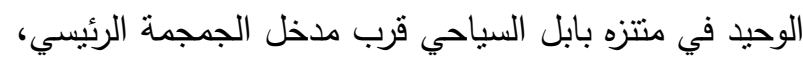

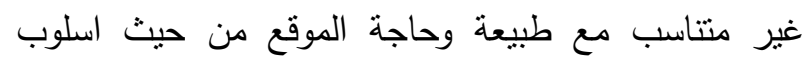

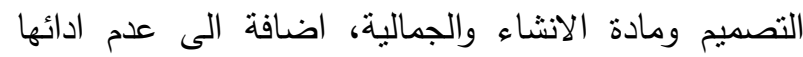
لوظيفتها بالثكل المطلوب كونها غير كافية لاستيعاب الهاب سيارات الزوار خلال ايام الزيارة القصوى للمتنزه. مدخل المتنزه الرئيسي (مدخل الجمجمة ) : يتضح من محاور

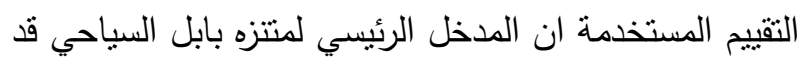
حقق نتائج جيدة ولجميع المحاور • الابنية: عكست نتائج تقييم الابنية الرئيسية جدول 4.

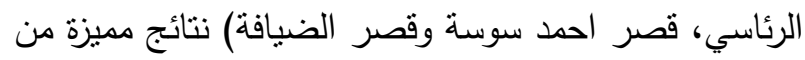
حيث حفاظها على اصالة وطابع تصميم المنتزه من خلال اسلوب تصميمها ومادة الانثاء، حيث تمت الاشارة إليها في من هن

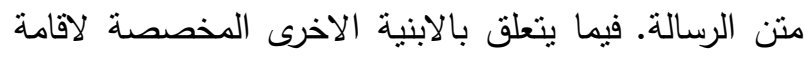
الاعراس و المناسبات، فأن اسلوب تصميمها لم يكن متلائما مع طبيعة الموقع وذلك بسبب كونها ابنية خدمية بالاصل

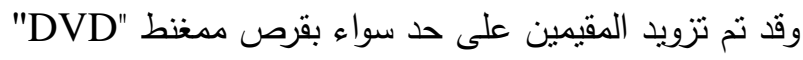

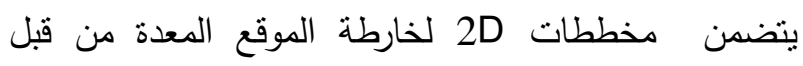

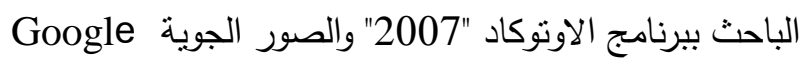

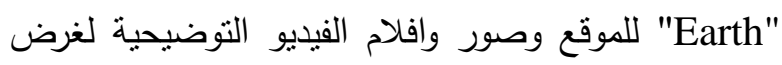
عرض صور وافلام واقع الحال وملف"Word" مرفق به به سيه جداول التقييم لواقع متنزه بابل السياحي وهي بالتسلسل الاتي:1-جدول تقييم المكونات الاصطناعية في المتتزه، وذلك من خلال خمسة محاور هي (اسلوب التصميم، مادة الصنع، ملائكتها لطبيعة الموقع، وظائفها، وجماليتها) ويحدد الئه

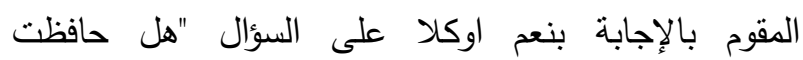
المكونات على طبيعة تصميم الموقع كمشهد "طبيعي - لخديه تاريخي".2- جدول تقييم فعاليات المتنزه، يحدد المقيم بالاجابة بمقياس متدرج ( نعم، كلا، الى حد ما ) على السؤال

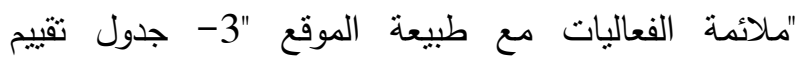

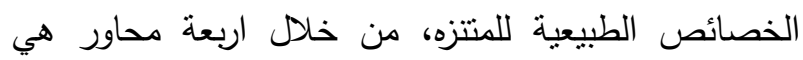
(تعدد انواعها، تعدد مواقعها، تعدد الصنع، ملائمتها لطبيعة

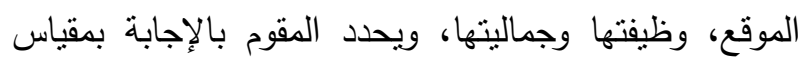

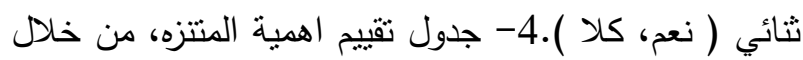

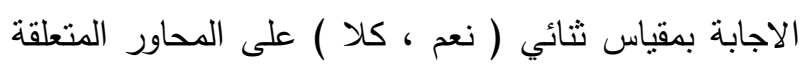

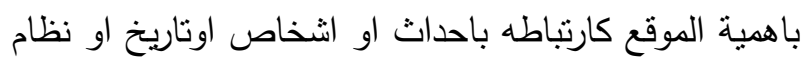

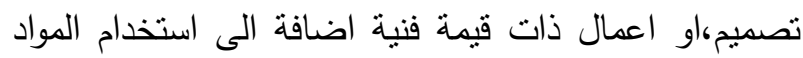
والايدي العاملة المحلية في تصميم وتتفيذ الموقع .5-جدول اعمل تقييم الغطاء النباتي، من خلال استخدام اربعة اوزان ترجيحية

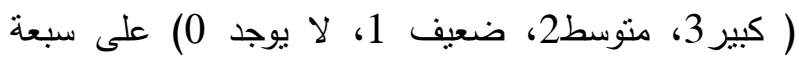

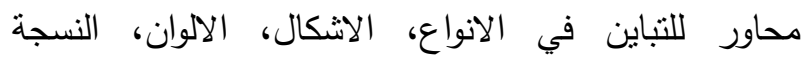


للحمايات الخاصة، وأنعكس ذلك على جماليتها، الا انها قد ادت وظائف معينة وبشكل جيد بالنسبة للمسرح الصيفي فقد.

$$
\text { جدول 4. تقييم المكونات الإنشائية في الموقع }
$$

\begin{tabular}{|c|c|c|c|c|c|c|c|c|c|c|c|c|c|c|}
\hline \multicolumn{15}{|c|}{ هل حافظت هذه المكونات على أصالة وطابع تصمصم الموقع (مشهـ طبيعي _ تاريخي)من } \\
\hline \multicolumn{2}{|c|}{ مردوخ } & \multicolumn{2}{|c|}{ الاعراس } & \multicolumn{2}{|c|}{ الضيافة } & \multicolumn{2}{|c|}{ قصر أحمد } & \multicolumn{2}{|c|}{ الرئاسي } & \multicolumn{2}{|c|}{ المتنزه } & \multicolumn{2}{|c|}{ السيارات } & \multirow{2}{*}{ المكونات الإصطناعية } \\
\hline كلا & 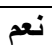 & كلا & نعم & كلا & نعم & كلا & نعم & كلا & نعم & كلا & نعم & كلا & نعم & \\
\hline 10 & $\mathbf{0}$ & 6 & 4 & 2 & 8 & 2 & 8 & 1 & 9 & 3 & 7 & 8 & 2 & أسلوب تصميمها \\
\hline 10 & $\mathbf{0}$ & 3 & 8 & 1 & 9 & 1 & 9 & 1 & 9 & 3 & 7 & 6 & 4 & المادة المصنو عة منها \\
\hline 6 & 4 & 2 & 8 & 2 & 8 & 1 & 9 & 1 & 9 & 3 & 7 & 8 & 2 & ملائمتها لطبيعة الموقع \\
\hline 3 & 7 & 2 & 7 & 2 & 8 & 1 & 9 & 4 & 6 & $\mathbf{0}$ & 10 & 7 & 3 & وظيفتها \\
\hline \multirow[t]{8}{*}{10} & $\mathbf{0}$ & 6 & 4 & 3 & 7 & 1 & 9 & 1 & 9 & & 7 & 10 & $\mathbf{0}$ & جماليتها \\
\hline & & \multicolumn{2}{|c|}{ شبكة } & \multicolumn{2}{|c|}{ التماثيل } & \multicolumn{2}{|c|}{ كازينو } & \multicolumn{2}{|c|}{ المطعم } & \multicolumn{2}{|c|}{ الصحكي } & \multicolumn{2}{|c|}{ الصيفي ح } & \\
\hline & & كلا & نعم & كلا & نعم & كلا & نعم & كلا & نعم & كلا & نعم & كلا & نعم & المكونات الإصطناعية \\
\hline & & 3 & 7 & 4 & 6 & 2 & 8 & 4 & 6 & 9 & 1 & 4 & 6 & أسلوب تصميمها \\
\hline & & 3 & 7 & 4 & 6 & 1 & 9 & 3 & 7 & 9 & $\mathbf{1}$ & 2 & 8 & المادة المصنو عة منها \\
\hline & & 3 & 7 & 4 & 6 & 1 & 9 & 3 & 7 & 6 & 4 & 2 & 8 & ملائمتها لطبيعة الموقع \\
\hline & & 3 & 7 & 6 & 4 & 1 & 9 & 3 & 7 & 6 & 4 & 2 & 8 & وظيفتها \\
\hline & & 5 & 5 & 7 & 3 & 3 & 7 & 4 & 6 & 10 & $\mathbf{0}$ & 4 & 6 & جماليتها \\
\hline
\end{tabular}

جدول 5. تقييم المكونات الإنشائية في الموقع ثانياً : تقييم الفعاليات في متنزه بابل السياحي:

\begin{tabular}{|c|c|c|c|c|c|c|c|c|c|c|c|c|c|c|}
\hline \multicolumn{15}{|c|}{ هل حافظت هذه المكونات على أصالة وطابع تصمصم الموقع (مشهر طبيعي - تاريخي)من } \\
\hline \multicolumn{2}{|c|}{ مردوخ } & \multicolumn{2}{|c|}{ الاعزاس } & \multicolumn{2}{|c|}{ الضيافة } & \multicolumn{2}{|c|}{ سوسة } & \multicolumn{2}{|c|}{ الرئاسي } & \multicolumn{2}{|c|}{ مدتل } & \multicolumn{2}{|c|}{ السيار اتف } & \multirow{2}{*}{ 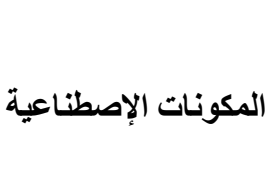 } \\
\hline كلا & نعم & كلا & نعم & كلا & نعم & كلا & نعم & كلا & نعم & كلا & نعو & كلا & نعم & \\
\hline 10 & $\mathbf{0}$ & 6 & 4 & 2 & 8 & 2 & 8 & 1 & 9 & 3 & 7 & 8 & 2 & أسلوب تصميمها \\
\hline 10 & $\mathbf{0}$ & 3 & 8 & 1 & 9 & 1 & 9 & 1 & 9 & 3 & 7 & 6 & 4 & المادة المصنوعة منها \\
\hline 6 & 4 & 2 & 8 & 2 & 8 & 1 & 9 & 1 & 9 & 3 & 7 & 8 & 2 & ملائمتها لطبيعة الموقع \\
\hline 3 & 7 & 2 & 7 & 2 & 8 & 1 & 9 & 4 & 6 & $\mathbf{0}$ & 10 & 7 & 3 & وظيفتها \\
\hline \multirow[t]{8}{*}{10} & $\mathbf{0}$ & 6 & 4 & 3 & 7 & 1 & 9 & 1 & 9 & 3 & 7 & 10 & $\mathbf{0}$ & جماليتها \\
\hline & & \multicolumn{2}{|c|}{ شبكة } & \multicolumn{2}{|c|}{ 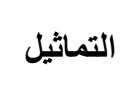 } & \multicolumn{2}{|c|}{ كازينو } & & & \multicolumn{2}{|c|}{ الصحكي } & \multicolumn{2}{|c|}{ الصيفي المسرح } & \\
\hline & & كلا & نعم & كلا & نعم & كلا & نعم & كلا & نعم & كلا & نعم & كلاّ & نعم & ات الإص \\
\hline & & 3 & 7 & 4 & 6 & 2 & 8 & 4 & 6 & 9 & 1 & 4 & 6 & أسلوب تصميمها \\
\hline & & 3 & 7 & 4 & 6 & 1 & 9 & 3 & 7 & 9 & 1 & 2 & 8 & المادة المصنوعة منها \\
\hline & & 3 & 7 & 4 & 6 & 1 & 9 & 3 & 7 & 6 & 4 & 2 & 8 & ملائمتها لطبيعة الموقع \\
\hline & & 3 & 7 & 6 & 4 & 1 & 9 & 3 & 7 & 6 & 4 & 2 & 8 & وظيفتها \\
\hline & & 5 & 5 & 7 & 3 & 3 & 7 & 4 & 6 & 10 & $\mathbf{0}$ & 4 & 6 & جماليتها \\
\hline
\end{tabular}

وجمالية بنسبة 60\%، أما بالنسبة لملائمته لطبيعة الموقع

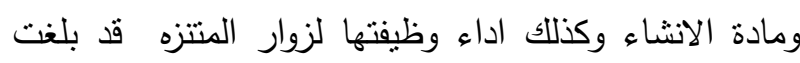
70 من التقييم.بالنسبة لشبكة الطرق والممرات فقد أظهرت النتائج بأن نسبة 70\% من المقييمين أيد بأن أسلوب تصميها

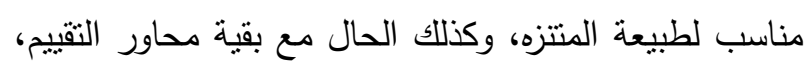

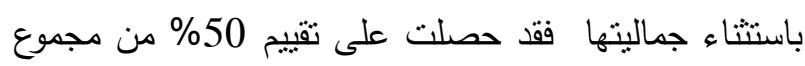
التقييم.أما بالنسبة إلى أثناث الموقع فظهر من خلال النتائج

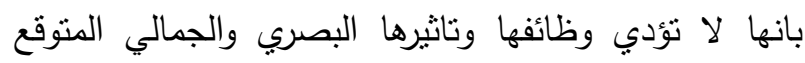

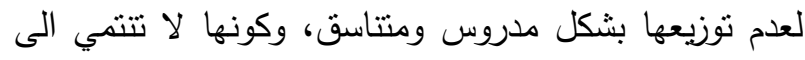

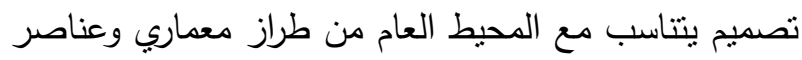

أظهرت نتائج جدول 4.انها ذات اسلوب تصميم وجمالية مناسبة لطبيعة الموقع، في حين مادة الانشاء والملائمة والاداء للوظيفة فقد حصلت على نتائج افضل وهذا ما اكدته فئه الملاحظة الموقعية للمنتزه خلص ايام الاعياد. تبين أن المركز

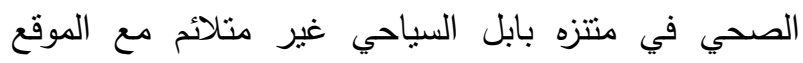

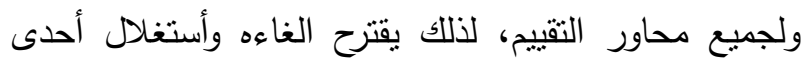
أبنية سويتات الأعراس كمركز صحي ملائم للموقع. تتكل المطاعم ومحلات تقديم الطعام في المنتزهات الجزء الاكبر في صناعة خدمة الطعام، وقد تنين من خلال نتائج التقييم أن المطعم في منتزه بابل السياحي يتمتع باسلوب تصميم 
أما بقية انواع الفعاليات (السفرات الترفيهية للمؤسسات

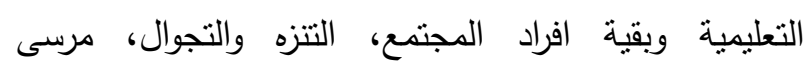
الزوارق)، فقد حصلت على تقييم 80\% على انها متلائمة مع طبيعة الموقع ، بينما حصلت فعالية اقامة حفلات تخرج طلبة الجامعات وحفلات الاعراس وفعالية المسرح المفتوح على 600 من التقييم، اما اعلى نسبة تقييم فقد كانت لصالح فعالية مراقبة الطبيعة، وهذا يعود إلى المناظر الطبيعية الجميلة المنمثلة بشط الحلة والنباتات التي تمثل البيئة الطبيعبة المحلية. ثالثا :- تقييم الخصائص الطبيعية لمتنزه بابل السياحي: نجد ان نتائج التقييم جاءت منوافقة مع تعدد انواع المشاهد الطبيعية من (البساتين نخيل، فاكهة، حمضيات، محاصيل الخضر)، ووظائفها المتعددة البيئية والجمالية والاحساس بالانتماء للمكان وبنسب عالية ومتقاربة، وكذلك الحال بالنسبة للطيور المحلية العصافير والبلابل داخل المتتزه، والبط والاوز والدجاج العراقي في القرى المجاورة، مما بعكس الاحساس بالبيئة المحلية للموقع والاصوات المتولدة منها ومن حركتها وديناميكيتها، وانواع الحشرات والنحل وغيرها من الحشرات المالوفة في بيئتا المحلية مما يولا الحركة وتدفق الحياة للموقع والذي يؤكد المشهد الطبيعي للموقع، كما موضتح في الجدول7.حيث تمت الاشارة إلى التفاصيل الخاصة وكذلك الصور التوضيحية في منن الرسال.
التاثيث الاخرى، كما أن عناصر الثاثثث الموجودة كواقع حال لا تكفي حاجة المنتزه، بإلإضافة إلى أن جميع عناصر التاثيث غير مصممة للمكان الذي وضعت فيه، بسبب كون المنتزه في البدء لم يصمم كمنتزه تاريخي طبيعي سياحي.جدول 5.وجميع الصور الخاصة بمكونات الموقع تمت الاثارة إليها في منن الرسالة. ثانياً : تقييم الفعاليات في متنزه بابل السياحي: عند النظر الى نتائج جدول 6. لتقييم الفعاليات في منتزه بابل السياحي نجد ان اقامة المؤتمرات في دار الضيافة وقصر احمد سوسة لم تجد صداها عند المقيمين لعدم تتاسبها مع طبيعة الخدمات المقدمة للزوار وانما تقتصر على فئة معينة واوقات خاصة، الا ان 40\% من اجابات المقيمين تؤيد طبيعة هذه الفعاليات ،في حين اقامة معارض الكتاب حازت على نسب منساوية بين من يؤكد بقاءها والى حد ما، جدول 6. تقييم الفعاليات في متنزه بابل السياحي

\begin{tabular}{|c|c|c|c|}
\hline \multicolumn{3}{|c|}{ 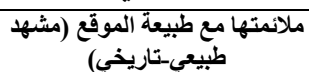 } & \multirow[t]{2}{*}{ الفعاليات } \\
\hline الى حد ما & كلا & نعم & \\
\hline $\mathbf{0}$ & 6 & 4 & 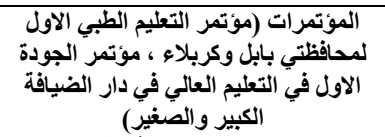 \\
\hline 4 & 2 & 4 & سوسة ، معرض باعة مبل الدولي في فلاستثمرار في \\
\hline 1 & 3 & 6 & حفلات التخرج والاعراس (قاعات \\
\hline 1 & 1 & 8 & السفرات الترفيهِية للمؤسستات التعليمية \\
\hline 0 & 0 & 10 & مر اقبة الطبيعة \\
\hline 2 & o & 8 & التنزه والتجوال \\
\hline 2 & 2 & 6 & مسرح \\
\hline 2 & 0 & 8 & مرسى الزوارق \\
\hline
\end{tabular}

جدول7. تقيم الخصائص الطبيعية في المتنزه رابعا : تقييم أهمية متنزه بابل السباحي.

\begin{tabular}{|c|c|c|c|c|c|c|c|c|c|c|}
\hline \multicolumn{11}{|c|}{ تقييم الخصائص الطبيعية } \\
\hline \multicolumn{2}{|c|}{ بياتئة طبيعية تمثل } & \multicolumn{2}{|c|}{ حيوانات التربية } & \multicolumn{2}{|c|}{ الحشرات } & \multicolumn{2}{|c|}{ الطيور المحلية } & \multicolumn{2}{|c|}{ مشهر طبيعي } & الظصيائص الظية \\
\hline كلا & 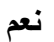 & كلا & ن نعم & كلا & 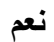 & كلا & نعم & كلا & ن عم & \\
\hline 1 & 9 & 7 & 3 & 1 & 9 & 2 & 8 & $\mathbf{0}$ & 10 & تعدد انواعها \\
\hline 2 & 8 & 2 & 8 & 2 & 8 & 3 & 7 & 1 & 9 & تعدد مواقعها \\
\hline 3 & 7 & 7 & 3 & 3 & 7 & 4 & 6 & 2 & 8 & تعدد وظائفها \\
\hline 2 & 8 & 6 & 4 & 2 & 8 & 2 & 8 & $\mathbf{0}$ & 10 & الاحساس بالموقع \\
\hline
\end{tabular}

بالنظر لما يتمتع به موقع متتزه بابل السياحي من اهمية لاسلوب تصميم معماري مميز ( تمثل بمدخل المتنزه الرئيسي، والقصر الرئاسي)، اضافة للمنطقة الاثرية(قصر نبوخذ نصر ،

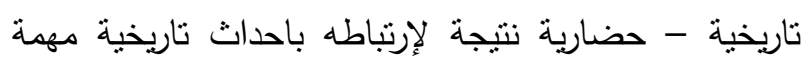
المسرح البابلي ... الخ )، ونفس النسبة تحققت بما يتعلق حضارة بابل (واشخاص لهم من التاثير والفاعلية في تطور بتضمن الموقع اعمال فنية منميزة (النقوش الفنية في القصور تاريخ العراق والعالم ( نبوخذ نصرو حمورابي)، فقد تبين من كقصر احمد سوسة والقصر الرئاسي، كما ان الايادي العاملة نتائج جدول8. ،ان تقييم المحاور الثناثة الاولى قد حصل على نسبة 100\% مما يؤكد على تحقق اهمية هذا الموقع التي قامت بكل هذه الاعمال الفنية والتصميمية من تخطيط وتصميم وتتفيذ هي عراقية محلية ( باستثاء بعض النقوش كشهد تاريخي، كما اكد 90\% من المقيمين تجسيد الموقع بله 
حجر في الموصل، والطابوق المنتج من معامل محلية.

المغربية- عمال مغاربة)، بالاضافة الى ان المواد المستخدمة

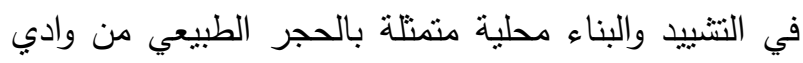

جدول 8. تقييم اهمية الموقع

\begin{tabular}{|c|c|c|}
\hline 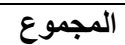 & & 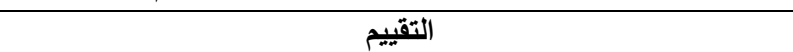 \\
\hline 10 & نعم & \multirow{2}{*}{ ارتبط الموقع باحداث مهمة لها تاثير في تاريخ البلا } \\
\hline $\mathbf{0}$ & كلا & \\
\hline 10 & نعم & \multirow{2}{*}{ ارتبط الموقع بحياة اشخاص هم من الاهمية في تاريخ وتطور البلد } \\
\hline $\mathbf{0}$ & كلا & \\
\hline 10 & نعم & \multirow[t]{2}{*}{ ارتبط الموقع بعصور التاريخ القديم او التاريخ الحديث } \\
\hline $\mathbf{0}$ & كلا & \\
\hline 9 & نعم & \multirow[t]{2}{*}{ تجسيد الموقع لاسلوب او نظام تصميم ( معماري وتصميم حدائق) محدد. } \\
\hline 1 & كلا & \\
\hline 9 & نعم & \multirow{2}{*}{ تضمن الموقع اعمال فنية تتمتع بقيمة فنية مميزة للموقع } \\
\hline 1 & كلا & \\
\hline 9 & نعم & \multirow[t]{2}{*}{ المواد المستخدمة في انشاء مكونات الموقع الاصطناعية ( محلية) } \\
\hline 1 & كلا & \\
\hline 10 & نعم & \multirow{2}{*}{ الايدي العاملة التي قامت بتخطيط وتصميم وتنفيذ الموقع ( محلية ) } \\
\hline $\mathbf{0}$ & كلا & \\
\hline
\end{tabular}

خامسا:- تقييم الغطاء النباتي في متنزه بابل السياحي: تم من قبل المقيمين يدويا باستخدام الاوزان الترجيحية وهي

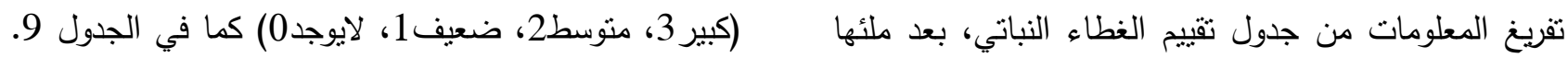
جدول (9) إجابات المقيمين للغطاء النباتي. لئي

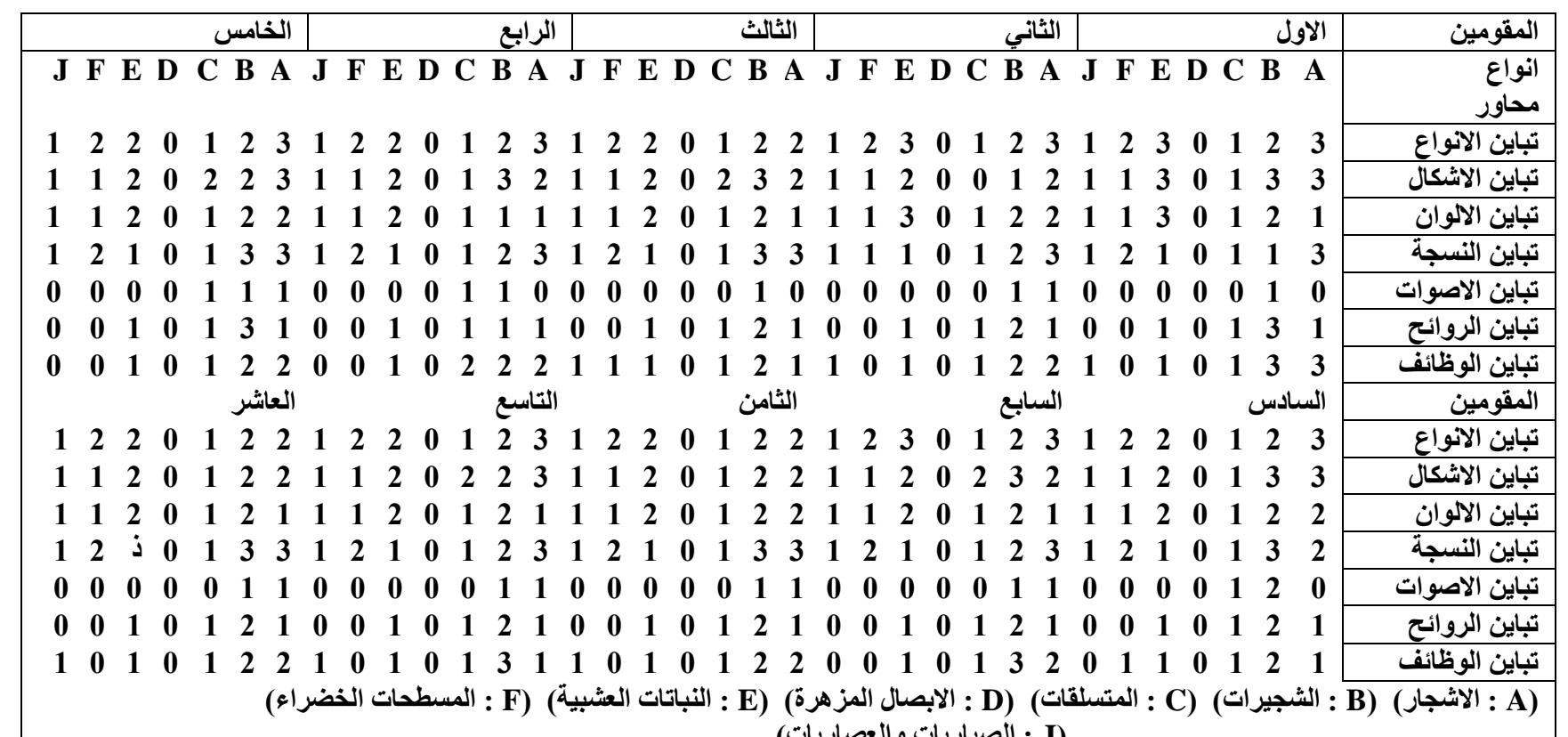
( الصباريات والعصاريات) : J)

الاثكال والنسجة فتباينها من كبير الى متوسط نوعا ما، في

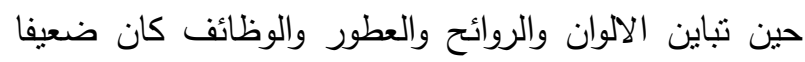

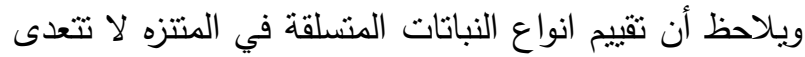
الضعيف الى متوسط من حيث الاشكال والانواع والالوان

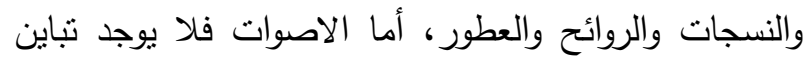

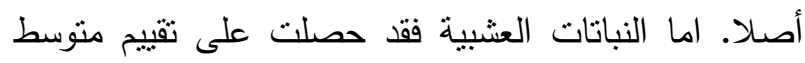
بالنسبة لتباين الانواع والاشكال والالوان، اما النسجة والروائح

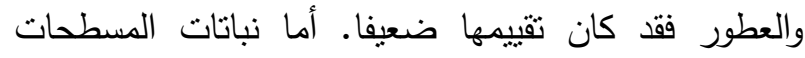
الخضراء المزروعة هي نفسها المستخدمة في معظم الحدائق
أجابات المقيمين للغطاء النباتي"، وتم أعداد جدول ببرنامج Excell,2010 Microsoft" جدول10. يتبين من خلا محاور التقييم المستخدمة لتقييم الغطاء النباتي لمتتزه بابل السياحي جدول10. أن الاثجار تميزت بتتوع كبير من حيث الانواع المزروعة وتباين نسجاتها

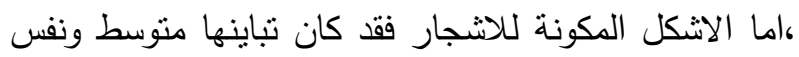

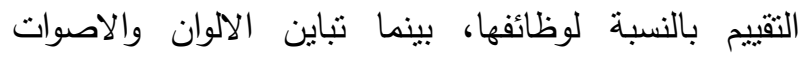

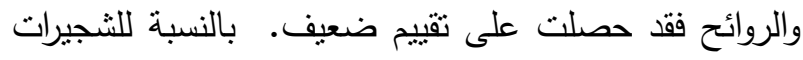
فقد كان نقييمها من حيث تباين النوع المزروع منوسط ، أما 
المزروعة، واشكالها والوانها ونسجتها، ولا يوجد اي تباين في

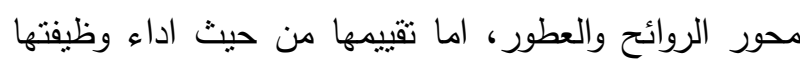
فكان متوسط.

والمتتزهات(الفرنسي، الامريكي) لذا فقد كان تقييمها من حيث تباين الانواع المزروعة متوسط، اما تباين الاثكال الالوان

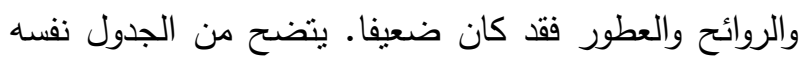

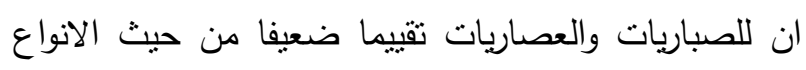
جدول 10. تقييم الغطاء النباتي.

\begin{tabular}{|c|c|c|c|c|c|c|c|c|}
\hline \multicolumn{9}{|c|}{ الانواع التباتية } \\
\hline والعصباريات الصبات & الخضر اءعحات & العشبية & الابصال & المتسلقات & الشجيرات & الاشجار & ترجيحية & محاور التباين \\
\hline $\mathbf{0}$ & $\mathbf{0}$ & 3 & $\mathbf{0}$ & $\mathbf{0}$ & $\mathbf{0}$ & 7 & \multirow{7}{*}{ كبير } & تباين الانواع المزروعة \\
\hline $\mathbf{0}$ & $\mathbf{0}$ & 1 & $\mathbf{0}$ & $\mathbf{0}$ & 5 & 4 & & تباين اشكالها \\
\hline $\mathbf{0}$ & $\mathbf{0}$ & 2 & $\mathbf{0}$ & $\mathbf{0}$ & $\mathbf{0}$ & $\mathbf{0}$ & & تباين الوانها \\
\hline $\mathbf{0}$ & $\mathbf{0}$ & $\mathbf{0}$ & $\mathbf{0}$ & $\mathbf{0}$ & 5 & 9 & & تباين نسجتها \\
\hline $\mathbf{0}$ & $\mathbf{0}$ & $\mathbf{0}$ & $\mathbf{0}$ & $\mathbf{0}$ & $\mathbf{0}$ & $\mathbf{0}$ & & تباين اصواتها \\
\hline $\mathbf{0}$ & $\mathbf{0}$ & $\mathbf{0}$ & $\mathbf{0}$ & $\mathbf{0}$ & 2 & $\mathbf{0}$ & & تباين الروائح والعطور \\
\hline $\mathbf{0}$ & $\mathbf{0}$ & $\mathbf{0}$ & $\mathbf{0}$ & $\mathbf{0}$ & 3 & 1 & & تباين الوظائف \\
\hline $\mathbf{0}$ & 10 & 7 & $\mathbf{0}$ & $\mathbf{0}$ & 10 & 3 & \multirow{7}{*}{ متوسط } & تباين الانواع المزروعة \\
\hline $\mathbf{0}$ & $\mathbf{0}$ & 9 & $\mathbf{0}$ & 4 & 4 & 6 & & تباين اشكالها \\
\hline $\mathbf{0}$ & $\mathbf{0}$ & 8 & $\mathbf{0}$ & $\mathbf{0}$ & 9 & 3 & & تباين الوانها \\
\hline $\mathbf{0}$ & 9 & $\mathbf{0}$ & $\mathbf{0}$ & $\mathbf{0}$ & 4 & $\mathbf{0}$ & & تباين نسجتها \\
\hline $\mathbf{0}$ & $\mathbf{0}$ & $\mathbf{0}$ & $\mathbf{0}$ & $\mathbf{0}$ & 1 & $\mathbf{0}$ & & تباين اصواتها \\
\hline $\mathbf{0}$ & $\mathbf{0}$ & $\mathbf{0}$ & $\mathbf{0}$ & $\mathbf{0}$ & 7 & $\mathbf{0}$ & & تباين الروائح والعطور \\
\hline $\mathbf{0}$ & $\mathbf{0}$ & $\mathbf{0}$ & $\mathbf{0}$ & 1 & 7 & 6 & & تباين الوظائف \\
\hline 10 & $\mathbf{0}$ & $\mathbf{0}$ & $\mathbf{0}$ & 10 & $\mathbf{0}$ & $\mathbf{0}$ & \multirow{7}{*}{ ضعيف } & تباين الانواع المزروعة \\
\hline 10 & 10 & $\mathbf{0}$ & $\mathbf{0}$ & 5 & $\mathbf{0}$ & $\mathbf{0}$ & & تباين اشكالها \\
\hline 10 & 10 & $\mathbf{0}$ & $\mathbf{0}$ & 10 & 1 & 7 & & تباين الوانها \\
\hline 10 & 1 & 10 & $\mathbf{0}$ & 9 & 1 & 1 & & تباين نسجتها \\
\hline $\mathbf{0}$ & $\mathbf{0}$ & $\mathbf{0}$ & $\mathbf{0}$ & 3 & 9 & 6 & & تباين اصواتها \\
\hline $\mathbf{0}$ & 10 & 10 & $\mathbf{0}$ & 10 & 1 & 10 & & تباين الروائح والعطور \\
\hline 6 & 2 & $\mathbf{0}$ & $\mathbf{0}$ & 9 & $\mathbf{0}$ & $\mathbf{0}$ & & تباين الوظائف \\
\hline $\mathbf{0}$ & $\mathbf{0}$ & $\mathbf{0}$ & $\mathbf{0}$ & $\mathbf{0}$ & $\mathbf{0}$ & $\mathbf{0}$ & \multirow{7}{*}{ لايوجد } & تباين الانواع المزروعة \\
\hline $\mathbf{0}$ & $\mathbf{0}$ & $\mathbf{0}$ & $\mathbf{0}$ & 1 & 1 & $\mathbf{0}$ & & تباين اشكالها \\
\hline $\mathbf{0}$ & $\mathbf{0}$ & $\mathbf{0}$ & $\mathbf{0}$ & $\mathbf{0}$ & $\mathbf{0}$ & $\mathbf{0}$ & & تباين الوانها \\
\hline $\mathbf{0}$ & $\mathbf{0}$ & $\mathbf{0}$ & $\mathbf{0}$ & 1 & $\mathbf{0}$ & $\mathbf{0}$ & & تباين نسجتها \\
\hline 10 & $\mathbf{0}$ & $\mathbf{0}$ & $\mathbf{0}$ & 7 & $\mathbf{0}$ & 4 & & تباين اصواتها \\
\hline 10 & $\mathbf{0}$ & $\mathbf{0}$ & $\mathbf{0}$ & $\mathbf{0}$ & $\mathbf{0}$ & $\mathbf{0}$ & & تباين الروائح والعطور \\
\hline 4 & 8 & $\mathbf{0}$ & $\mathbf{0}$ & $\mathbf{0}$ & $\mathbf{0}$ & 3 & & تباين الوظائف \\
\hline
\end{tabular}

18- 20 دونم ، أرتفاعه العمودي 35م في حين يبلغ

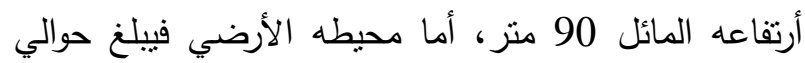

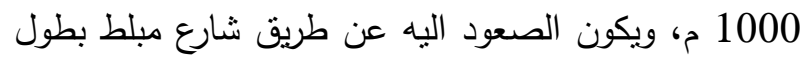

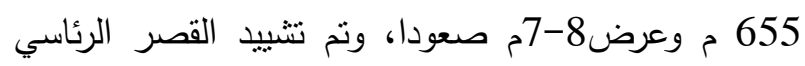
عليه. التلة مقسمة إلى عشر قطع بشكل منلثات وكل قطعة مرقمة برقم قطعة رقم 1، قطعة رقم 2 وهكذا،مزروعة بإنواع مختلفة من النباتات منها اثجار الالبيزيا، وشجيرات الياسمين

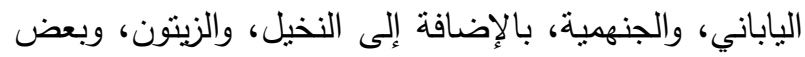

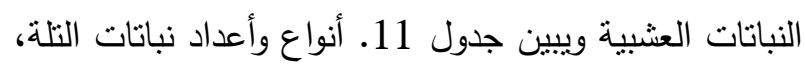
حيث يثير الصف الأول لجميع القطع إلى أعداد النباتات المزروعة سابقاً، في حين يثير الصف الثاني من القطعة رقم 3 ولغاية القطعة رقم 9 إلى أعداد الثتلات المضافة حديثاً،

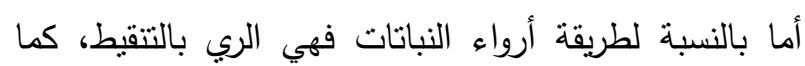

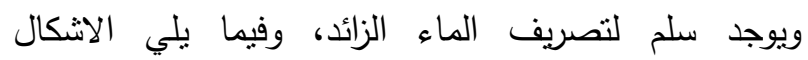

أعداد مخططات واقع الحال والمقترحات التصميمية لموقع التثة والقصر: بالنظر لكون موقع التل في متنزه بابل

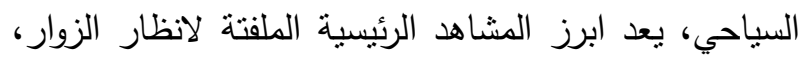

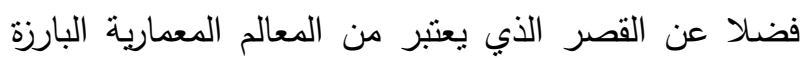

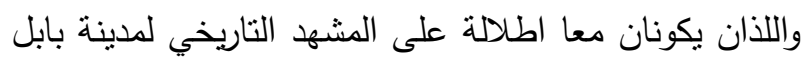
القديمة والمشهد الطبيعي لمدينة الحلة ، لذا فقد وقع الاختيار على هذا الموقع لدراسة واقعه واعداد المقترحات التصميمية المناسبة التي تهدف الى تطويره بما يتلائم واهمية الموقع

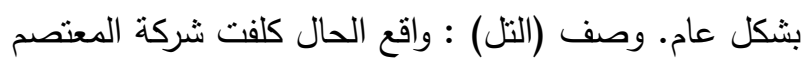
العراقية للمقاولات أنذاك بأنثاء ثنلات تنال واع أصطناعية في مناطق متفرقة من محافظة بابل، الأول قرية الجمجمة

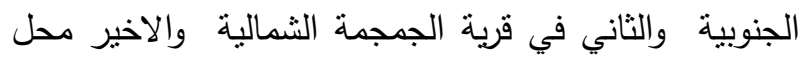

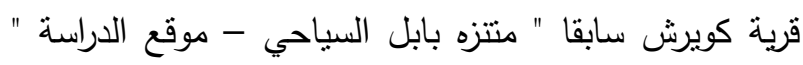
حاليا، وأطلق على التلة إنذاك " تل صدام" تنبلغ مساحته 


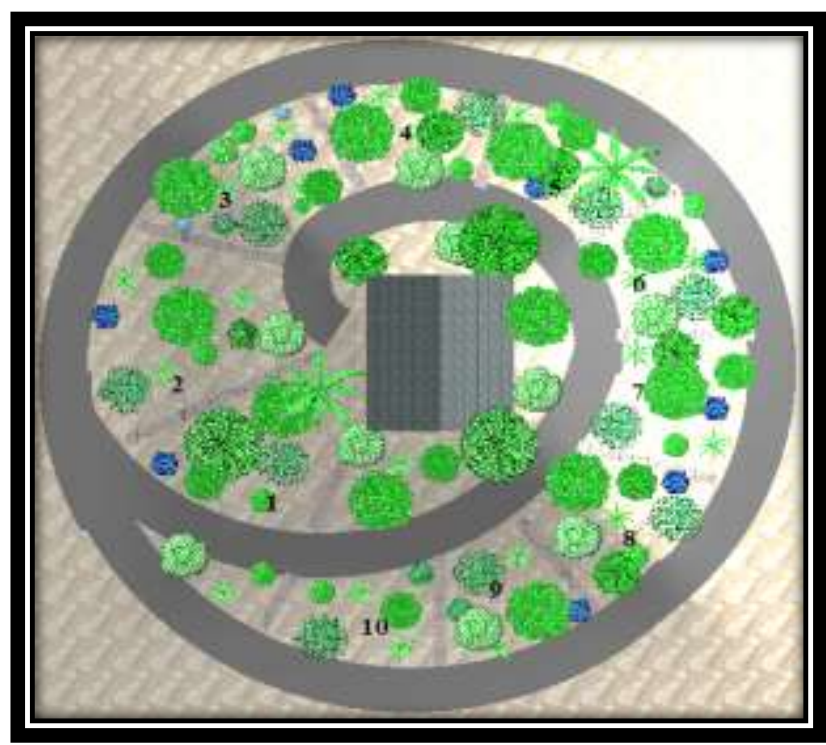

شكل 6. مخطط 3D للتل مع القصر والنباتات

وصف مقترح تصميم التل من مان

جنائن بابل المعلقة احدى عجائب الدنيا السبع في العالم القديم، وذكر انها بنيت في مدينة بابل القديمة في عهد الملك نبوخذ نصر الثاني، وكتب عنها العديد من مؤرخي اليونان بان

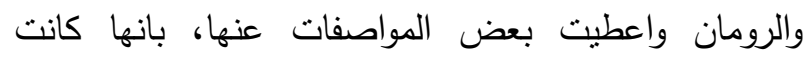
محاطة بجدار محصن وان لها مدرجات نتصل ببعضها بسلالم،ومملؤة بنباتات الزينة المختلفة، كالاشجار والزهور (6). التصميم المقترح لموقع التلة حاول ان يجسد في مضمونه

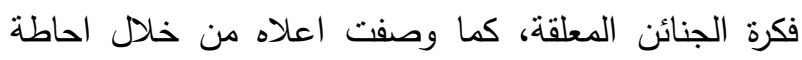
جوانب شوارع التلة بجدار حجري يصل ارتفاعه الى نصف

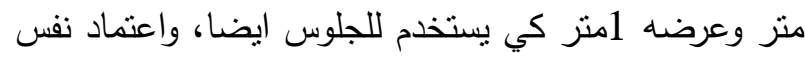
التقسيم للتلة (القطع العشرة) الا انها تقسم بسلالم لتسهيل صعود الزائر والاستمتاع بالمنظر وعلى ارتفاعات مختلفة، واحاطة جوانب السلالم بنباتات اسيجة(الأس)، اما مساحة القطع فيراعى انثاء ممرات بسيطة فيها لسهولة اجراء عمليات الخدمة مستقبلا، ويفضل زراعتها بالمتسلقات المزهرة والتي تستخدم كمغطى تربة ايضا بشكل منتاسق من حيث موعد ولون التزهير، كان يكون مجموعة جهنميات،مجموعة لمديه

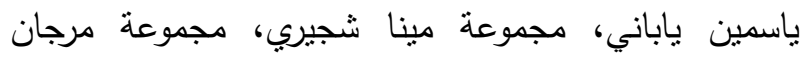
منسلق، فضلا عن استغلال الطابق العلوي مجاور القصر مابله بتوزيع اماكن جلوس شكل(7) يوضح مخططات التصميم

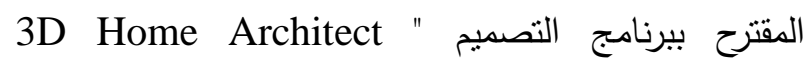
2D 3. Design Suite Deluxe8
التوضيحية لواقع الثلة، مع المخططات الثنائية وثلاثية الابعاد

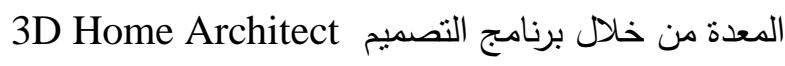
"Design Suite Deluxe 8"

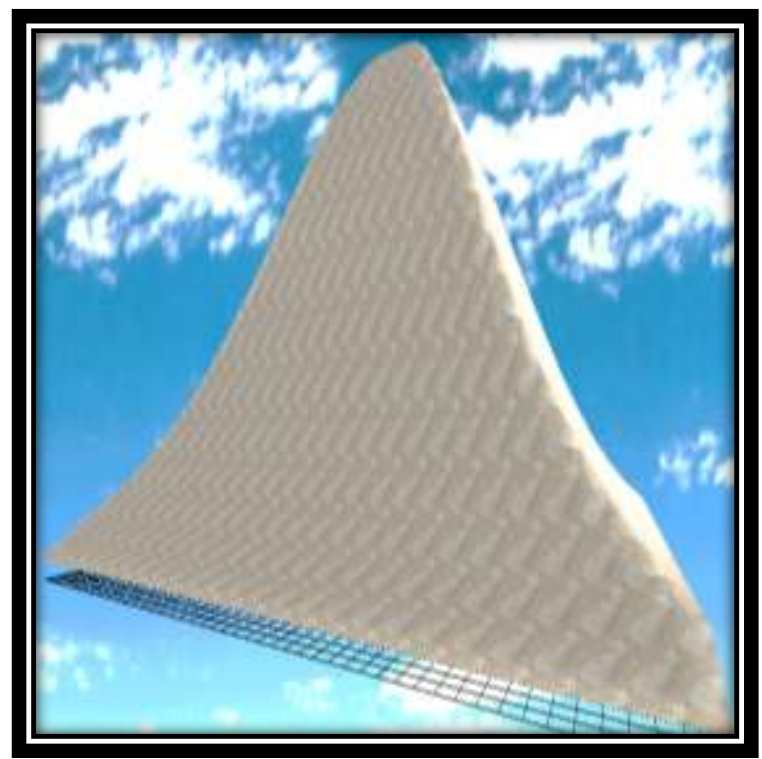

شكل 3.مخطط ثلاثي الابعاد للتلة

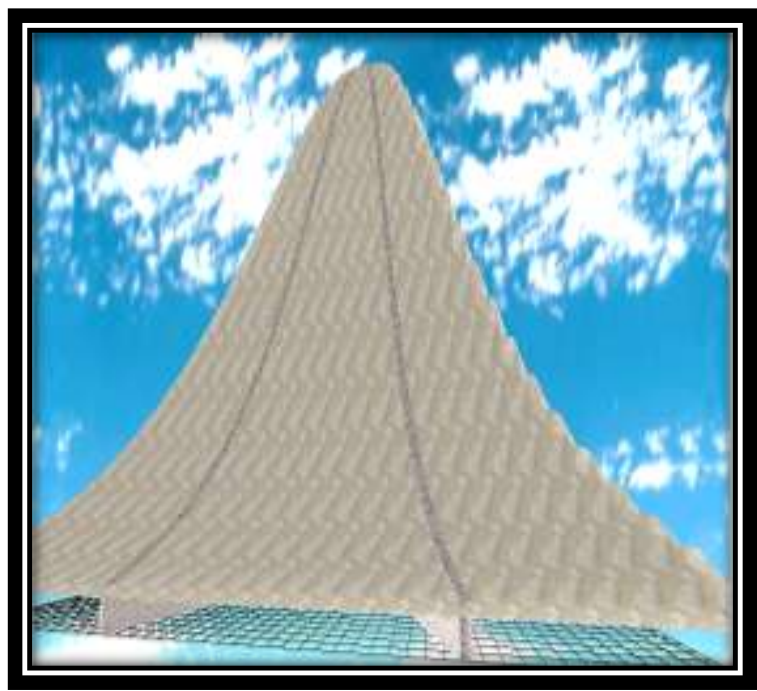

شكل4. مخطط 3D يوضح تقسيمات التلة

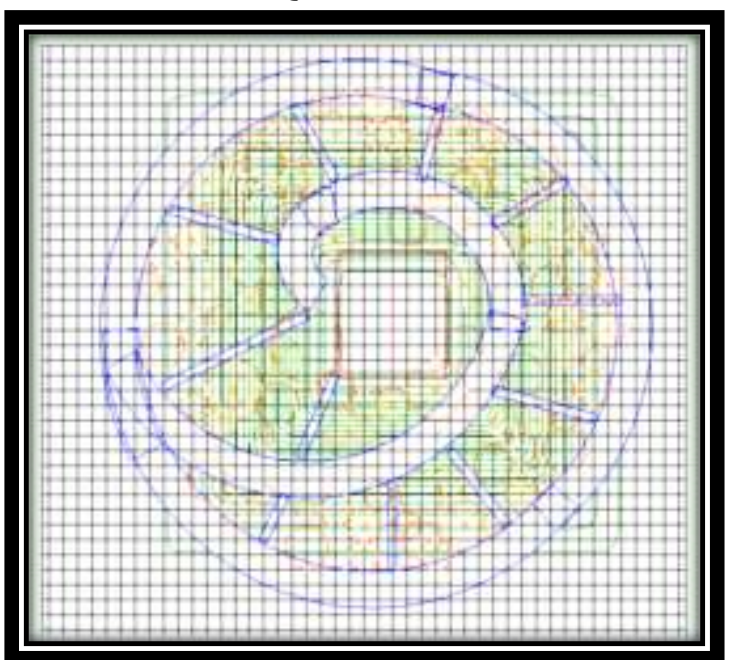

شكل 5. مخطط 2D للتل والشوارع والنباتات 

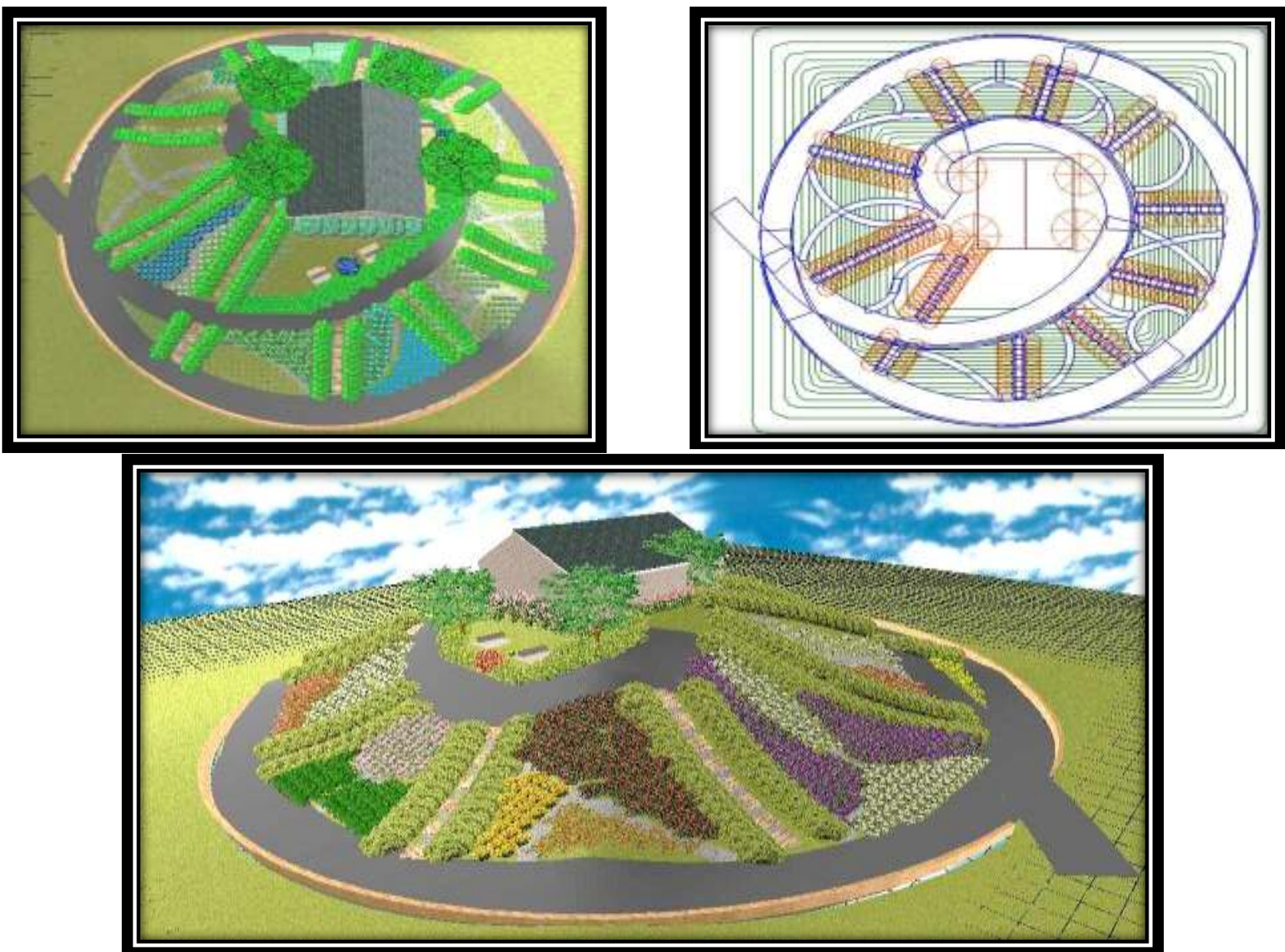

شكل 7. يوضح مخططات المقترح التصميمي

جدول12.رموز نباتات التلة

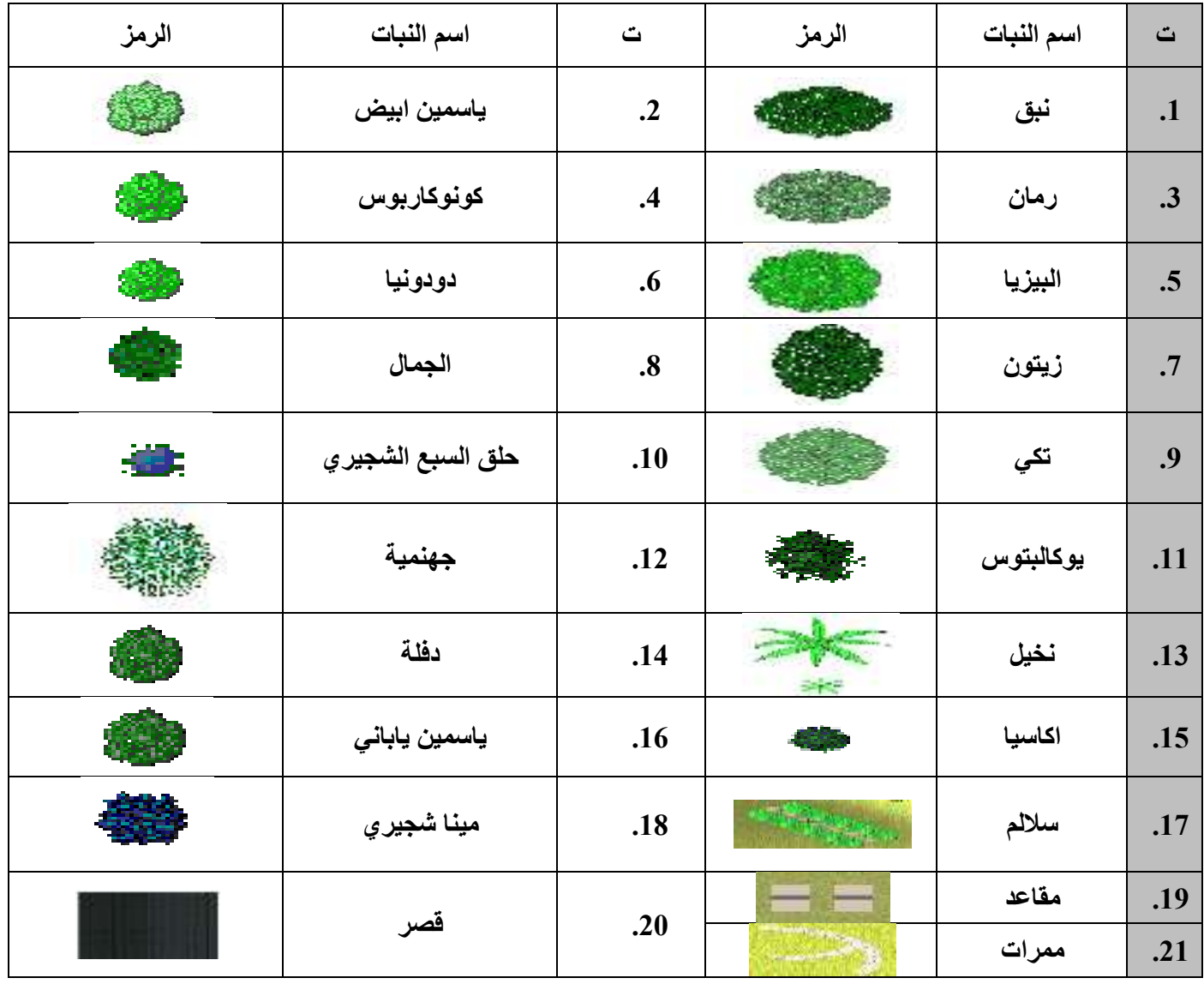




\section{جدول 11. يوضح أنواع وأعداد النباتات على التل}

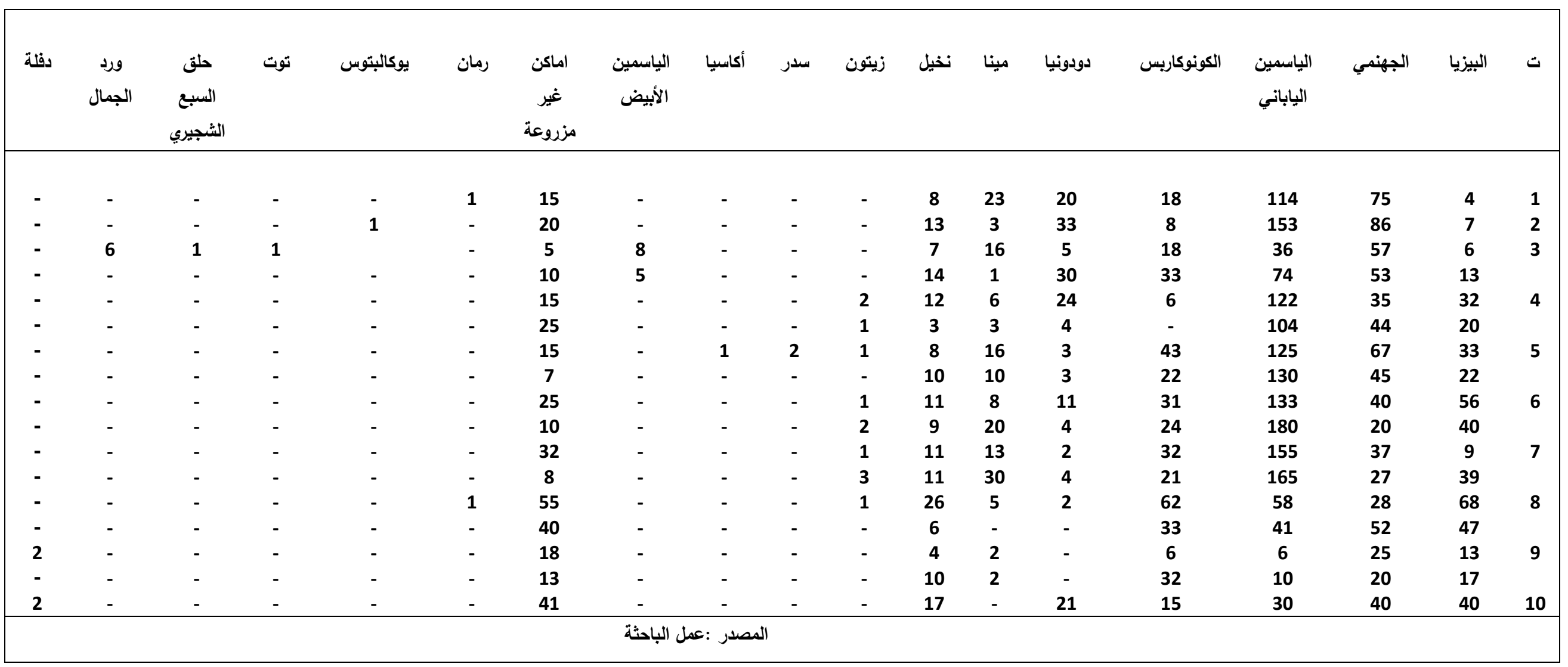




\section{REFERENCE}

1.Abbawi, R. F. N. 2008. The Role of Fourt Dimension in Achieving Sensory Pleasure for the Receiver in Landscpe Architecture Analytic Study for the Design Prop erties.(Ph.D). University of Technoology, Department of Architecture. Iraq.PP:205 Landsape of urban Parks. Case Study AlAzhar Park Ports and Engineering Research journal, Cairo.PP:1-14.

3.Abdul Hamid,A. S. and H. K. Al-Faran 2009.The importance of the design chara cteristics of the visual and aesthetic elements "analytical study of the center of the city ofNablus," (M.T) in Urban and Regional Planning, An-Najah National University. Palestine.PP:1-31.

4.Al-Chalabi, S.K. and N.K. Al-hyat. 2013. Ornamental Plants in Iraq. Store Bookshop University of Baghdad. Iraq. p:416. .AlJa nabi,T,M.2008.Publicadministration budg ets.Zahran Store for Publushing Amman. Jordan.

6.Alomary,A.Y.2013.Hanging gardens of babylon or hanging gardens of ninewa "comparative study of their landscape spatialcharacteristics.Al-Rafidian. Engineering Journal.(22)2: 1-15.

7.Alqiei,T.M.2007.Design and Landscaping The Fifth Edition, Knowledge Facility for Printing and Publishing, Alexandria-Arab Republic of Egypt, p.263.

8.Al-Sultan,S. M. T. M. Al-Chalabi and M. D. Alsawaf. 1992.Ornament.Bookshop Store for Printing and Publishing. University of Mosul. Iraq. P:464.

9.Chiesura, A. 2004. Therole of urban parks for the sustainabl city:Landscape and Urban Planning. Department of Leisure, Tourism and Environment, Wageningen University Wagen -ingen. Netherlands 68:129-138.
10.Clement, D. 1999. General Guidelines for Identifying and Evaluating Historic Lands cape. Environmental Program. Calif -ornia Department of Transportation, Sacram -ento ,California.US.PP:27.

11.Doherty, J. M. K. R. Meier, L.Erics and M. Z. Steiriti. 2005. An Introduction to Historic Landscape Preservation. Massachusetts Dep. of conservation and Recreation (DCR) Executive office of Environmental Affairs. U.S.A.PP:1-13.

12.Eckbo,G. 2006. Urban Landscape Design. Published by Mc Graw Hill (TX)U.S.APP:150.

13.Keller,Genevieve,P.1993.The inventory and analysis of historic landscapes ,HistoricL andscapePreservatio.(7)3:26-35.

14.Keller,J. T and G. Keller.2003. How to Evaluate and Nominate Designed Historic Landscapes.National Register Bulletin 18,DC:National Park Service. Washin gton .PP:1-14.

15.Mahmoud M. K.1993. Effect of green space on the maximum temperatures and minor in the city of Baghdad during the summer period. Journal of Agricultural Scie nce. 24 (1)PP:135-146.Iraq.

16.McClelland, L. J. T. Keller and R. Z. Melnick. 1990. Guidlines for Evaluating and Documenting Rural Historic Landscapes. National.Register.Bulletin.

30.Washington.DC:NationalPark.Service ,Bas -ic Source for Evaluating Vernacular Landsc apes.PP:1-25.

17.Mohamad Roslan, M. K. and M. I. Nurashikin.2012.Public Parks Aesthetic Value Index,Principal Component Analysis Multidis -ciplinary Applications. niversitiP Utra Malaysia-Malaysia.PP:212. 